\title{
Emerging Therapies for Multiple Sclerosis
}

\author{
Paolo A. Muraro* and Bibiana Bielekova ${ }^{\dagger}$ \\ *Department of Cellular and Molecular Neuroscience, Imperial College London, London SW7 2AZ, United Kingdom; ${ }^{\dagger}$ Waddell \\ Center for Multiple Sclerosis, Department of Neurology, University of Cincinnati and The Neuroscience Institute, Cincinnati, OH \\ 45267-0538
}

\begin{abstract}
Summary: This review examines the mode of action, safety profile and clinical efficacy of some of the most promising new therapeutic strategies for multiple sclerosis. Autologous hematopoietic stem cell transplantation can regenerate a new and tolerant immune system and is a potentially effective rescue therapy in a subset of patients with aggressive forms of MS refractory to approved immunomodulatory and immunosuppressive agents. High-dose cyclophosphamide without stem cell support is suggested to induce prolonged remissions through similar immunological mechanisms with less toxicity. Fingolimod (FTY720) is a novel oral immunomodulating agent that acts through preventing lymphocyte recirculation from lymphoid organs. Monoclonal antibody therapy has provided scientists and clinicians the opportunity to ratio-
\end{abstract}

nally direct the therapeutic intervention against specific molecules. Targeting molecules of the immune system such as CD52 (alemtuzumab), CD25 (daclizumab), VLA-4 (natalizumab) and CD20 (rituximab) have resulted in potent immunomodulatory effects through sometimes unpredicted mechanisms. The potential of immunoglobulins to induce remyelination in the CNS is being investigated in an attempt to develop therapies promoting tissue repair and functional recovery. The evidence supporting the potential of these emerging immunotherapies suggests that strong progress is being made in the development of effective cures for multiple sclerosis. Key Words: Multiple sclerosis, hematopoietic stem cell transplantation, fingolimod, monoclonal antibodies, remyelination.

\section{INTRODUCTION}

More than a decade after the introduction of interferon- $\beta$, a new wave of immune-modifying therapies for multiple sclerosis (MS) is being advanced. In this article we discuss a selection of therapies that have attracted great interest regarding the mechanism of action and clinical effects. This review is not intended to be exhaustive, and some promising treatments were not covered because of space restrictions. The treatments we discuss have been found to exert effects on the immune system that were not always predicted by the rationale for their experimentation and often evade the conventional boundaries between immunosuppressive and immunomodulatory therapies.

\footnotetext{
Address correspondence and reprint requests to: Paolo A. Muraro, Division of Neuroscience and Mental Health, Faculty of Medicine, Imperial College, Charing Cross Campus, St. Dunstan's Road, London W6 8RP, United Kingdom. E-mail: p.muraro@imperial.ac.uk; or Bibiana Bielekova, Waddell Center for MS, University of Cincinnati, 231 Albert Sabin Way, MSB 4458, Cincinnati, OH 45267-0538. E-mail: bibi.bielekova@uc.edu.
}

\section{HEMATOPOIETIC STEM CELL TRANSPLANTATION}

High-dose immunosuppressive therapy (HDIT) followed by hematopoietic stem cell transplantation, often simply referred to as hematopoietic stem cell transplantation (HSCT), is an experimental therapeutic approach that is being explored in autoimmune diseases including MS. The ambitious goal of high-dose immunosuppressive therapy/HSCT is to significantly modify the course of the disease, ideally inducing a complete and stable remission from disease activity, through a single albeit multistep medical intervention. The attractive hypothesis that stem cells in the hematopoietic graft could migrate to and repair the damaged organs target of inflammation, thus leading to functional recovery, has raised considerable interest for the early clinical experiences, but it has also resulted in some semantic confusion. The evidence supporting the integration into the CNS and transdifferentiation of cells of hematopoietic origin into neural cells is controversial. ${ }^{1-5}$ Experimental allergic encephalomyelitis (EAE) studies observed that autoimmune demyelination could be prevented or arrested after clinical onset, but established damage could not be reversed. ${ }^{6,7}$ Whether 


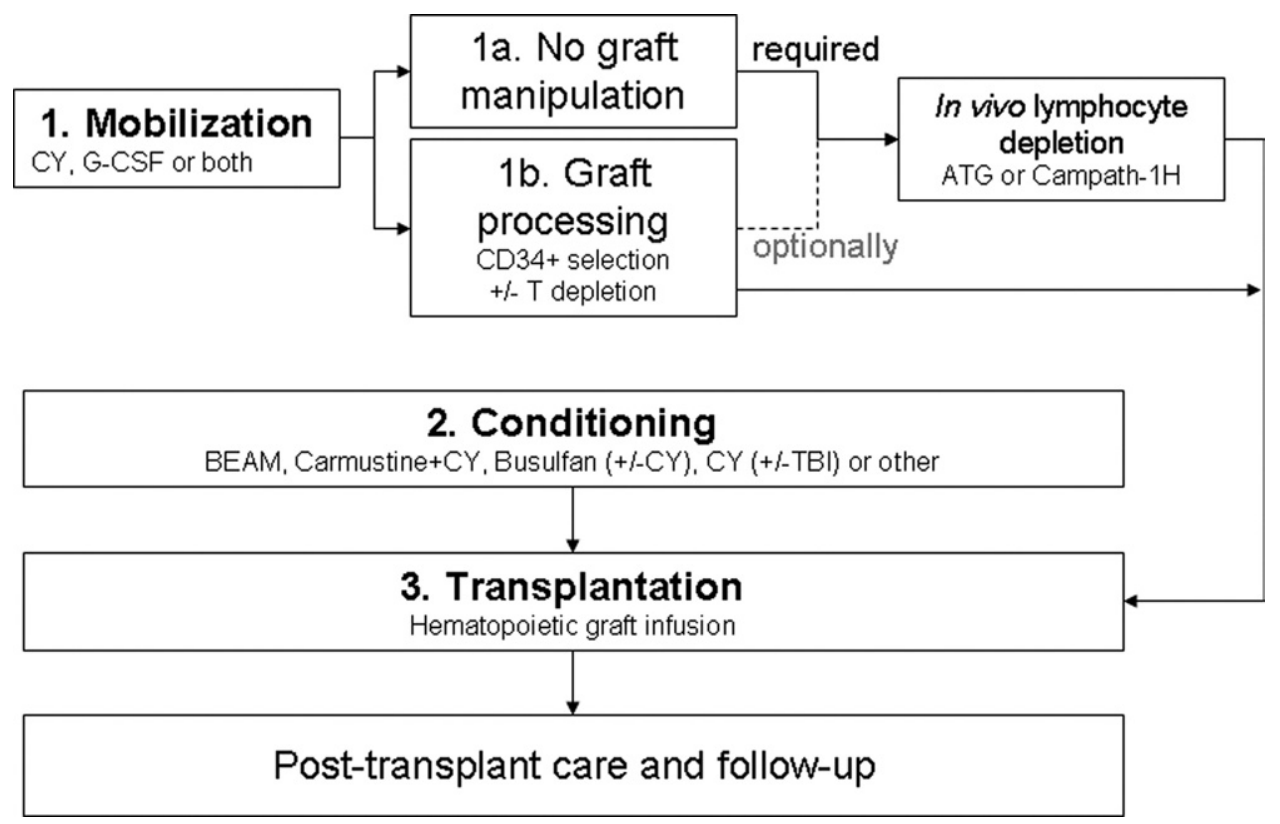

FIG. 1. Block diagram of autologous hematopoietic stem cell transplantation. Autologous hematopoietic stem cell transplantation consists of three main steps: 1) Mobilization of hematopoietic stem cells (HSC) from the bone marrow into the blood, followed by harvest and cryopreservation of the graft (1a) or purification of hematopoietic stem cell (HSC) by CD34+ selection (1b); 2) Conditioning, consisting of chemotherapy and/or radiation to ablate the immune system; and 3) Transplantation of the autologous HSC. Lymphocyte depletion with anti-thymocyte globulin (ATG) or Campath-1H is required to eliminate in vivo mature immune cells that are reinfused with unmanipulated grafts; it is an option to maximize immune suppression when the graft is CD34+ selected. (ATG, anti-thymocyte globulin; BEAM, carmustine, etoposide, cytosine-arabinoside, and melphalan; CY, cyclophosphamide; G-CSF, granulocyte colony-stimulating factor; TBI, total body irradiation.)

hematopoietic cell infusion may promote neural or oligodendroglial repair to a greater degree than what could be expected from spontaneous recovery during disease remission remains unknown and requires further investigation. In this review we will focus on HSCT and its effects regarding the correction of abnormalities in the immune system as opposed to the potential of stem cells to promote CNS tissue repair, which is discussed elsewhere in this issue (see Imitola's article, page 701, in this issue).

\section{Treatment schemes}

HSCT can be performed by reinfusing the (autologous) hematopoietic cells of the patient or those from a human leukocyte antigen-matching (allogeneic) donor. Systematic clinical experience in MS is limited to autologous HSCT. Currently, most neurologists do not believe that the theoretically greater efficacy of allogeneic transplantation can outweigh the increased morbidity and mortality risks for MS. Allogeneic HSCT could be experimented as a salvage therapy for patients with a severe course of MS who failed all other treatment options including autologous HSCT. ${ }^{8}$ There are individual cases of patients with MS who were later diagnosed with a hematologic malignancy and then underwent allogeneic HSCT. ${ }^{9}$ A systematic reassessment of these cases is in progress (R. Nash, personal communication, with permission). The HSCT treatment scheme consists of three main steps: 1) hematopoietic stem cell harvest, 2) immunosuppressive conditioning and 3) hematopoietic stem cell infusion. The regimens used in different protocols varied. A schematic outline of the most common possibilities is presented in Figure 1. Hematopoietic stem cells have been harvested by bone marrow aspiration, or much more frequently, by mobilization to the peripheral blood followed by leukapheresis. Graft manipulation consisted of CD34+ selection, or in few protocols, lymphocyte depletion was achieved by negative selection with antibodies or with incubation of the graft with lymphotoxic agents. When the graft is reinfused without manipulations, anti-thymocyte globulin (ATG) is required as a form of in vivo lymphocyte purging. ATG can also be given after $\mathrm{CD} 34+$ selected graft reinfusion to achieve maximum intensity of lymphocyte depletion. The heterogeneity of regimens that were used in experiments may have important implications for the safety, tolerability and efficacy of treatment. However, low numbers and different composition of the patient groups treated make a definitive comparison problematic.

\section{Mechanisms of action}

The basic rationale for use of this therapy for autoimmune diseases is to exploit the effects of immune suppression and reconstitution so as to regenerate a new and healthy immune system. This notion, often termed "immune resetting," remained speculative until recently. Re- 
cent studies have corroborated that hypothesis by demonstrating the regeneration of a new T-cell repertoire after autologous HSCT in patients with MS. ${ }^{10}$ The renewed T-cell repertoire was more clonally diverse than pretreatment and was found in connection with a boost in thymic output ("thymic rebound") during long-term immune reconstitution. The mechanisms by which immune reconstitution after HSCT can favor tolerance over autoimmunity have been discussed in detail elsewhere. ${ }^{11}$ An exciting observation in patients with juvenile idiopathic arthritis who benefited from HSCT was the increase of $\mathrm{CD} 4+\mathrm{CD} 25+$ regulatory $\mathrm{T}$ cells, ${ }^{12}$ a possibility that needs to be investigated in MS. These studies have challenged the assumption that the results of HSCT on the course of disease were simply the effect of profound immunosuppression. However, answering the question as to whether HSCT can indeed permanently restore immune tolerance will only be possible after very long-term clinical and laboratory follow-up of treated patients. As discussed below, there is growing evidence of clinical remissions persisting for several years after immune reconstitution in the absence of any maintenance therapy.

\section{Clinical experience}

At the time of this writing, worldwide registries include more than 350 cases of MS patients who underwent auto-HSCT. The European Group for Blood and Marrow Transplantation has registered 280 patients who received an auto-transplant for MS in Europe and Asia (R. Saccardi, personal communication, with permission). The Center for International Blood and Marrow Transplant Research registry has reported 77 autologous transplants and one allogeneic transplant for MS between 1996 and 2005 in America. ${ }^{13}$

\section{Safety}

Major risks and side effects are associated with HSCT. Saccardi et al ${ }^{14}$ analyzed the history of treatment-related mortality (TRM) in the European Group for Blood and Marrow Transplantation registry for MS. Nine of 169 patients that could be evaluated had died for reasons connected to the transplantation (ie, an overall TRM of $5.3 \%$ ). Infection was involved as the cause for six of these deaths. However, TRM was only observed until the end of year 2000; no treatment-related deaths were recorded after that date. This analysis suggests that factors such as accumulating clinical experience with MS in transplantation and appropriate patient selection have improved the safety of treatment. In addition, there was no TRM in the group of 53 patients who received the carmustine, etoposide, cytosine-arabinoside, and melphalan (BEAM) + ATG + unmanipulated graft regimen. Underlying differences in toxicity among different regimens is the most likely explanation, but a transplant center effect can not be ruled out. This analysis indicates that the notion of 5 to $10 \%$ mortality prevailing in the neurological community is probably outdated. According to many transplant hematologists, today the risk of treatment-related death for an autologous HSCT to a patient in good general conditions should not exceed $1 \%$. The incidence of acute side effects such as gastrointestinal disturbances and alopecia (often reversible) is high $(>50 \%)$. Less frequently, infections, neutropenic fever, engraftment syndrome, transient neurological deterioration, bleeding and organ failure can complicate the clinical course. Late risks include gonadal insufficiency, infertility and secondary malignancies. There is vast literature on toxicities in the hematology/oncology setting, but the information can not be easily extrapolated to the different population of patients with MS who ordinarily do not have major organ dysfunctions (e.g., dysfunctions of the lung, heart, kidney or liver) nor are predisposed to malignancies (as with cancer patients). The European and American Registries will allow in due course for the evaluation of long-term toxicities.

\section{Efficacy}

A summary of characteristics and results of clinical studies of HSCT in MS is shown in Table 1; this includes the most recent publications from prospective studies in which 10 or more patients were treated and followed for a median duration of at least 2 years. ${ }^{15-21}$ There are limitations to consider when examining these data, such as heterogeneous patient populations and transplantation regimens, small number of patients, and lack of a control arm, and yet some points emerge clearly. A high proportion of patients (72 to $100 \%$ ) showed no appearance of enhancing or new lesions by MRI and had no relapses for the duration of follow-up. These data must be interpreted with caution because the treated patient population was constituted for the most part by patients with progressive MS; therefore, these patients were less likely to have relapses and enhancing lesions. However, almost complete suppression of focal inflammatory disease activity was convincingly demonstrated in a protocol that required the presence of contrast-enhancing lesions at baseline MRI scans and used triple-dose gadolinium. ${ }^{19,22}$ Initial quantitative assessments of brain atrophy has reported evidence of brain volume loss in the first year post-transplantation. ${ }^{23-25}$ However, evaluation of long-term effect (i.e., 5 years) has shown, in addition to confirming the virtually complete suppression of focal inflammatory MRI activity, a much lower rate of brain atrophy after the second year of follow-up than previously observed short-term. ${ }^{26}$ Several factors may influence development of brain atrophy and its MRI measures, including pseudo-atrophy, neurotoxicity from busulfan ${ }^{25}$ or total body irradiation, ${ }^{16,17}$ and gliosis, rendering the interpretation of results very difficult in the absence of sufficient baseline information and a treatment control arm. The evaluation 
TABLE 1. A Selection of Studies of Autologous Hematopoietic Stem Cell Transplantation in Patients with Multiple Sclerosis

\begin{tabular}{|c|c|c|c|c|c|c|c|c|}
\hline $\begin{array}{l}\text { Reference } \\
\text { (No.) }\end{array}$ & $\begin{array}{l}\text { No. of } \\
\text { Patients } \\
\text { Treated }\end{array}$ & MS Subtype & $\begin{array}{l}\text { EDSS at } \\
\text { Inclusion } \\
\text { (Range) }\end{array}$ & $\begin{array}{l}\text { Conditioning } \\
\text { Regimen }\end{array}$ & $\begin{array}{c}\text { Fatal or Life-Threatening } \\
\text { Adverse Events }\end{array}$ & $\begin{array}{l}\text { Follow-Up Median } \\
\text { (Range) }\end{array}$ & $\begin{array}{l}\text { Response on } \\
\text { Inflammatory Activity } \\
\text { (MRI or Relapses) }\end{array}$ & $\begin{array}{c}\text { Response on } \\
\text { Neurological Disability } \\
\text { (EDSS) }\end{array}$ \\
\hline $\begin{array}{l}\text { Fassas et al., } \\
2000(15)\end{array}$ & 24 & $\begin{array}{l}13 \text { SPMS, } 8 \text { PPMS, } \\
3 \text { PRMS }\end{array}$ & $4.5-8.0$ & BEAM + ATG & $\begin{array}{l}1 \text { death from aspergillosis; } \\
1 \text { liver VOD, } 1 \text { TTP }\end{array}$ & 40 mo $(21-51)$ & $\begin{array}{l}\text { No enhancing lesions } \\
\text { in } 21 / 23(91 \%)\end{array}$ & $\begin{array}{l}\text { 18/23 (78\%) stabilized } \\
\text { or improved }\end{array}$ \\
\hline $\begin{array}{l}\text { Nash et al., } \\
2003 \text { (16) }\end{array}$ & 26 & $\begin{array}{l}17 \text { SPMS, } 8 \text { PPMS, } \\
1 \text { RRMS }\end{array}$ & $5.0-8.0$ & $\mathrm{TBI}+\mathrm{ATG}$ & $\begin{array}{l}1 \text { death from EBV-related } \\
\text { posttransplantation } \\
\text { lymphoproliferative disorder }\end{array}$ & 24 months (3-36) & $\begin{array}{l}\text { No new or enhancing } \\
\text { lesions in } 21 / 25 \\
\text { ( } 84 \%) \text {; one clinical } \\
\text { deterioration with } \\
\text { engraftment } \\
\text { syndrome }\end{array}$ & $\begin{array}{l}\text { 19/25 (76\%) stabilized } \\
\text { or improved }\end{array}$ \\
\hline $\begin{array}{l}\text { Burt et al., } \\
2003 \text { (17) }\end{array}$ & 21 & $\begin{array}{l}14 \text { SPMS, } 6 \text { PRMS, } \\
1 \text { RRMS }\end{array}$ & $3.0-8.5$ & $\mathrm{CY}+\mathrm{TBI}$ & $\begin{array}{l}2 \text { deaths from complications of } \\
\text { neurological deterioration }\end{array}$ & 24 months $(5-60)$ & $\begin{array}{l}\text { No new or enhancing } \\
\text { lesions in } 13 / 18 \\
\text { ( } 72 \%) \text {; one } \\
\text { confirmed relapse } \\
\text { at } 14 \text { months }\end{array}$ & $\begin{array}{l}13 / 21(62 \%) \text { stabilized } \\
\text { or improved } \\
\text { [9/9 patients with } \\
\text { pre-Tx EDSS } \\
3.0-6.0 ; \text { and } 4 / 12 \\
\text { patients with } \\
\text { EDSS }>6.0 \text { ] }\end{array}$ \\
\hline $\begin{array}{l}\text { Saiz et al., } \\
2004 \text { (18) }\end{array}$ & 15 & 9 SPMS, 6 RRMS & $4.5-6.5$ & $\begin{array}{l}\mathrm{BCNU}+\mathrm{CY}+ \\
\text { ATG }\end{array}$ & None & 36 months (19-55) & $\begin{array}{l}\text { No enhancing lesions } \\
\text { in } 15 / 15(100 \%) ; \\
\text { confirmed relapses } \\
\text { in } 2 \text { patients }\end{array}$ & $\begin{array}{l}12 / 15(80 \%) \text { stabilized } \\
\text { or improved }\end{array}$ \\
\hline $\begin{array}{l}\text { Saccardi et al., } \\
2005 \text { (19) }\end{array}$ & 19 & 15 SPMS, 4 RRMS & $5.0-6.5$ & $\mathrm{BEAM}+\mathrm{ATG}$ & $\begin{array}{l}1 \text { gastric ulcer bleeding } \\
\text { requiring endoscopic } \\
\text { intervention }\end{array}$ & 36 months (12-72) & $\begin{array}{l}\text { No enhancing lesions } \\
\text { in } 18 / 19(95 \%)\end{array}$ & $\begin{array}{l}18 / 19(95 \%) \text { stabilized } \\
\text { or improved }\end{array}$ \\
\hline $\begin{array}{l}\text { Ni et al., } 2006 \\
\quad(20)\end{array}$ & 21 & $\begin{array}{l}16 \text { SPMS, } 2 \text { PPMS, } \\
2 \text { PRMS, } 1 \\
\text { malignant MS }\end{array}$ & $5.0-9.5$ & $\begin{array}{l}\text { BEAM (20) or } \\
\text { CY + TBI (1) }\end{array}$ & $\begin{array}{l}2 \text { deaths from pneumonia (1) } \\
\text { and VZV hepatitis (1) }\end{array}$ & 42 months (6-65) & $\begin{array}{l}\text { No enhancing lesions } \\
\text { in } 18 / 21(86 \%)\end{array}$ & $\begin{array}{l}16 / 19(84 \%) \text { stabilized } \\
\text { or improved }\end{array}$ \\
\hline $\begin{array}{l}\text { Samijn et al., } \\
2006(21)\end{array}$ & 14 & SPMS & $5.5-6.5$ & $\begin{array}{l}\mathrm{CY}+\mathrm{TBI}+ \\
\mathrm{ATG}\end{array}$ & $\begin{array}{l}\text { EBV-related posttransplantation } \\
\text { lymphoproliferative disorder } \\
\text { (1), myelodysplastic } \\
\text { syndrome (1). One death } \\
\text { from respiratory infection } 5 \\
\text { years from transplantation }\end{array}$ & 36 months (7-36) & $\begin{array}{l}\text { No enhancing lesions } \\
\text { in } 14 / 14(100 \%)\end{array}$ & $\begin{array}{l}5 / 14(36 \%) \text { stabilized or } \\
\text { improved }\end{array}$ \\
\hline
\end{tabular}

Except for Saccardi et al. ${ }^{19}$ no study required presence of enhancing MRI lesions pretransplantation for patient inclusion.

The definition of stabilization varied with some studies requiring unchanged EDSS change and others allowing a change of 0.5 points.

ATG, anti-thymocyte globulin; BEAM, carmustine, etoposide, cytosine-arabinoside and melphalan; BU, busulfan; CY, cyclophosphamide; EBV, Epstein-Barr virus; EDSS, Expanded Disability Status Scale; MS, multiple sclerosis; PPMS, primary progressive multiple sclerosis; PRMS, progressive-relapsing multiple sclerosis; RRMS, relapsing-remitting multiple sclerosis; SPMS, secondary progressive multiple sclerosis; TBI, total body irradiation; TTP, thrombotic thrombocytopenic purpura; VOD, veno-occlusive disease; VZV, varicella-zoster virus. 
of disability outcomes is also complex and must take into account that the majority of patients who entered the study had high disability scores (Expanded Disability Status Scale [EDSS] score, 6.0 and greater), although some protocols allowed the inclusion of patients with moderate disability scores. Although the clinical deterioration pretreatment required per inclusion criteria could implicate some contribution of a regression to the mean of the observed outcome, it is an insufficient explanation for the stabilization or improvement post-therapy that was observed in the majority of patients in all studies (Table 1) except one. ${ }^{21}$ Furthermore, detailed scrutiny of the clinical data reveals that continued worsening of disability post-therapy was more frequently observed in patients who had a severe and established degree of disability prior to HSCT. This observation parallels the findings obtained in trials of Campath- $1 \mathrm{H}^{27}$ (see the section on Campath-1H as follows in this article), suggesting that chronic deterioration in HSCT-treated patients was more likely related to axonal and oligodendroglial degenerative processes rather than being related to a failure to suppress an active inflammatory process. A recently published histopathologic analysis of autopsy brains from subjects who died after receiving HSCT has shown ongoing CNS demyelination and axonal injury in association with activated microglia, in spite of suppressed inflammation post-transplantation. ${ }^{28}$

Several limitations preclude generalizing these data as a comprehensive and definitive assessment of pathological outcomes after HSCT for MS. The analysis was performed in five subjects with advanced disability (EDSS scores, 5.5 to 8.0), three of whom died within 2 months or less from HSCT. The causes of death suggest that systemic infection and hypoxia may have contributed to the observed microglial activation. Notwithstanding these confounding factors, the analysis is valuable in pointing out microglial activation as a possible mechanism of disease, which HSCT, as well as other "peripheral" immune interventions, is likely to fail to modify. We have recently observed that bone marrow transplantation (BMT) applied to mice in the late phase of EAE development resulted in different clinical outcomes. Mice that were transplanted with lower clinical scores underwent complete clinical remission post-blood and marrow transplantation, whereas worsening in those with higher scores was not prevented. Numbers of activated macrophage/microglial cells were significantly greater in mice that progressed, and tracking of green fluorescent protein-transduced blood and marrow cells showed the endogenous origin of the activated microglia. ${ }^{29}$ These data suggest that microglial activation may play a role in the clinical progression observed in chronic advanced stages of autoimmune demyelination. The hypothesis that BMT/HSCT in advanced progressive MS, in spite of profound effects on components of the adaptive immune system (T lymphocytes), does not prevent activated microglia from maintaining an inflammatory/toxic CNS environment resulting in progressive axonal and oligodendroglial damage, would reconcile the observations from clinical trials, our EAE data and the autopsy data by Metz and colleagues. ${ }^{28}$ Testing this hypothesis will require further studies in administering HSCT to patients with an aggressive course of disease who have failed immune-modifying treatments but have not reached the stage of chronic progressive deterioration that is often associated with advanced secondary progressive MS.

\section{Ongoing studies}

We know of four clinical studies that are currently open worldwide; two are randomized, open-label trials: 1) the Autologous Stem Cell Transplantation International Multiple Sclerosis Trial (ASTIMS; www.astims. org), and a study of nonmyeloablative hematopoietic transplantation using cyclophosphamide (CY) + ATG (principal investigator, R. Burt, Northwestern University, Chicago, IL). The control arms for the two studies are mitoxantrone and approved standard of care (licensed immunomodulatory/immunosuppressive drugs), respectively. Two single arm studies are also recruiting patients: 1) the HALT-MS trial, a multicentric trial funded by the United States National Institutes of Health (principal investigator, R. Nash, Seattle, WA) using carmustine, etoposide, cytosine-arabinoside, and melphalan (BEAM)-ATG + CD34+ selection as the conditioning regimen; and 2) a study of reduced intensity hematopoietic transplantation (principal investigator, G.L. Mancardi, Genoa, Italy) sponsored by the Italian Multiple Sclerosis Society.

\section{Perspective}

We believe HSCT needs to be further evaluated as a treatment modality for cases at the severe end of the spectrum of MS. Its efficacy, however, should be tested in the appropriate patient population, having learned the lessons from previous trials of HSCT and having taken into account an increased understanding of the pathophysiological evolution of MS. HSCT may be beneficial in patients who have an aggressive course of relapsingremitting (RR) MS but still demonstrate low disability and high inflammatory activity. In contrast, subjects who have already reached advanced progressive stages of the disease are unlikely to receive benefit from suppression of peripheral inflammation. Given the risks involved with HSCT, patients with ominous prognostic features should be identified as candidates and treated before they have significantly, and perhaps irreversibly, deteriorated. The conundrum is our limited ability to accurately identify patients at high risk for poor prognosis.

Clinical trials have used inclusion criteria similar to those identified in 1998 at the Milano consensus conference. ${ }^{30}$ There is a need to replace these reasonable, good 
judgment-based criteria with quantitative predictors of risk of unfavorable prognosis. ${ }^{31}$ Neuroimaging studies may assist in the selection of RR MS patients with high inflammatory activity and poor tissue repair ${ }^{32}$ who may be the most suitable candidates for early aggressive intervention, as suggested by individual cases included in larger studies ${ }^{10,16,17}$ or separately reported. ${ }^{33}$

In conclusion, HSCT remains a highly experimental treatment that should only be offered to selected patients in the context of a clinical study, whenever possible. When participation in a trial is not possible, and treatment with HSCT is considered on a compassionate basis, expert review of the appropriateness of indication and reporting to a registry for data collection is recommended before proceeding.

\section{HIGH-DOSE CYCLOPHOSPHAMIDE "REBOOTING"}

Administration of cyclophosphamide (CY) at chemotherapy doses (e.g., $50-200 \mathrm{mg} / \mathrm{Kg} /$ day for 4 days) can maximally deplete lymphoid cells without myelosuppression, thus not requiring hematopoietic stem cell support. This approach, pioneered by investigators at Johns Hopkins University, ${ }^{34}$ has been termed high-dose cyclophosphamide (HDC) "rebooting" to suggest the presumed mechanism. As a cytotoxic drug, CY is more active on lymphocytes than granulocytes. At lower doses, CY has immunomodulatory properties. ${ }^{35,36}$ At increasing doses, CY induces pancytopenia but spares hematopoietic stem cells, which express high levels of aldehyde dehydrogenase that inactivate its active alkylating metabolites. As a result, maximal lymphoid suppression is followed by mobilization and proliferation of bone marrow-derived hematopoietic stem cells. Granulocyte colony-stimulating factor (G-CSF) can be administered to hasten neutrophil recovery. HDC "rebooting" has some practical and conceptual advantages as well as disadvantages compared to HSCT. The safety and tolerability seems to be better for HDC, although the number of cases treated is much more limited. HDC does not carry the risk to reinfuse mature immune cells that "contaminate" the autologous stem cell graft in HSCT. The suggested conceptual advantage is counterbalanced in that the degree of ablation of mature immune cells is predicted to be considerably lower with HDC than with myeloablative transplantation regimens. Because it is not known how transplantation intensity affects clinical efficacy, it is currently not possible to predict whether the efficacy of HDC will differ from more intensive regimens.

One recent study has examined the safety and efficacy of HDC in a group of 13 patients with severe refractory MS. ${ }^{37}$ All had active disease in spite of a minimum of two approved disease-modifying therapies. Six patients had RR MS and seven had secondary progressive MS, and approved treatment failure was defined as two or more relapses (for RR MS) or objective deterioration (for secondary progressive MS) in the previous year. The patients had moderate to advanced disability (EDSS scores range, 4.0-8.0) and a wide range of disease duration (3.1 to 29 years). Only expected toxicities were observed, consisting of neutropenic fever (six patients), nausea and transient serum chemistry abnormalities. Duration of neurological follow-up was limited in time, reaching 24 months for only two patients, and ranging from 6 to 18 months in the remaining subjects. Five patients $(42 \%)$ had a decrease in their EDSS score of 1.0 point or more, and no patient had a sustained worsening. An MRI evaluation reported a stabilization of the number of lesions, but no conclusive statement could be made on the effects of treatment on the frequency of active lesions because only two patients had enhancing lesions (one lesion each) pretherapy. Interestingly, the study detected improvement in quality-of-life measures. This observation, together with the report by Saccardi et al. ${ }^{19}$ in HSCT, suggests that for the majority of subjects the beneficial effects of the intervention on their overall health status has overridden the immediate side effects experienced during chemotherapy. Although limitations of this study (notably a small and heterogeneous group of patients and short follow-up) preclude definitive statements, HDC "rebooting" is a promising experimental treatment for severe MS and warrants additional studies. Indeed, HDC and HSCT are the only therapies existing today that have the potential to "cure" the immune system and induce a persistent, medication-free remission from new disease activity in subjects with MS.

\section{FINGOLIMOD (FTY720)}

FTY720 is a synthetic analog of sphingosine 1 phosphate (S1P), a pleiotropic mediator released by platelets during inflammation. Interestingly, FTY720 was first obtained by chemical modification of ISP-I (myriocin), a natural immunosuppressant derived from Isaria sinclairii, a fungus used in traditional Chinese medicine. ${ }^{38} \mathrm{~S} 1 \mathrm{P}$ is present in serum at relatively high concentrations, whereas the concentration in thymus and lymph nodes is low. In vivo, FTY720 is metabolized to (S)-enantiomer of FTY720-phosphate by sphingosine kinase 2. The active metabolite FTY720-phosphate acts as a powerful agonist on four out of the five known sphingosine receptors: $\mathrm{S}_{1} \mathrm{P}_{1}, \mathrm{~S}_{1} \mathrm{P}_{3}, \mathrm{~S}_{1} \mathrm{P}_{4}$ and $\mathrm{S}_{1} \mathrm{P}_{5}$, but not $\mathrm{S}_{1} \mathrm{P}_{2} \cdot{ }^{39}$ These are G-protein coupled receptors that deliver a recognition signal for lymphocytes to egress the thymus and secondary lymphoid tissues. Engagement of S1P receptors leads to their internalization resulting in loss of the lymphocytes to have the ability to leave the lymphoid organs. Analysis of $\mathrm{S} \mathrm{P}_{1}$-deficient fetal liver chimeras has shown 
that $\mathrm{S}_{1} \mathrm{P}_{1}$ is essential for lymphocyte recirculation from both the thymus and peripheral lymphoid organs. ${ }^{40} \mathrm{~A}$ recent study confirmed and extended these findings by showing that migration of CD4+ cells is dependent on $\mathrm{S} 1 \mathrm{P}_{1} \cdot{ }^{41} \mathrm{FTY} 720$ also modulates dendritic cell (DC) functions ${ }^{41-44}$; among those, DC migration and endocytosis are suppressed via an effect on $\mathrm{S}_{1} \mathrm{P}_{3}{ }^{41}$

Sequestration of lymphocytes in secondary lymphoid organs prevents the cells from trafficking to the tissues target of inflammation. The immunosuppressive pharmacological properties of FTY720 were first tested in animal models of tissue transplantation, demonstrating suppression of allograft rejection in different species and of graft versus host disease (see Chiba et al. ${ }^{45}$ for a comprehensive review). Subsequent studies have examined the immunosuppressive effects of FTY720 in experimental models of inflammation, including EAE. The FTY720 treatment almost completely prevented the induction of EAE in Lewis rats ${ }^{46,47}$ and attenuated the course of established disease in rats ${ }^{47}$ and SJL mice. ${ }^{48}$ Mechanisms other than S1P-R modulation are likely to contribute to the clinical effects of the drug. These actions include modulation of important mediators of inflammation. FTY720 has inhibitory effects on cytosolic phospholipase A2, the rate-limiting enzyme of production of arachidonic acid-derived eicosanoids. ${ }^{49}$ Down-regulation of interleukin (IL)-12 p70 and induction of CD4+ $\mathrm{CD} 25+$ regulatory $\mathrm{T}$ cells has been shown in association with suppression of T-helper 1-mediated inflammation by FTY720. ${ }^{50}$ Notably, the $\mathrm{S} 1 \mathrm{P}-\mathrm{S} 1 \mathrm{P}_{1}$ axis has recently been shown to be capable of inducing IL-17 activity, and the observed suppressive effect of FTY720 on S1P augmentation of Th17-cell development may have an important role in the mode of action in inflammatory disorders of the drug. ${ }^{51} \mathrm{~S} 1 \mathrm{P}$ receptors are widely expressed in the CNS, and effects observed on astrocytes could be of relevance to treatment of MS. FTY720 induces extracellular signal-related kinase (ERK) phosphorylation on rat astrocyte cultures ${ }^{52}$ and stimulates astrocyte migration. ${ }^{53}$ The biological effects of these changes remain to be assessed in vivo.

Oligodendrocytes express $\mathrm{S}_{1} \mathrm{P}_{1}, \mathrm{~S}_{1} \mathrm{P}_{2}, \mathrm{~S}_{1} \mathrm{P}_{3}$ and $\mathrm{S} 1 \mathrm{P}_{5}$, and the recent demonstration that FTY720 reduces the migration of oligodendrocyte precursors in vitro via an effect on $\mathrm{S}_{1} \mathrm{P}_{5}$ raises the concern that the drug may negatively affect remyelination in $\mathrm{MS},{ }^{54}$ a possibility that also needs to be addressed by in vivo studies.

The first human tests of FTY720 were for renal transplant rejection prophylaxis. Phase I and phase II studies showed good tolerability and efficacy in preventing acute rejection in de novo transplant recipients (reviewed in reference ${ }^{55}$ ). These studies also described the pharmacokinetics, characterized by a prolonged absorption phase, a long half-life $(\sim 200 \mathrm{~h})$ and a large volume of distribution, consistent with the lipophilic properties of the drug. Recently, two large phase III clinical trials examining FTY in combination with cyclosporine A (CsA) at full- or reduced-dose versus mycophenolate mofetil plus cyclosporine A showed that FTY was equally effective to mycophenolate mofetil, but only in association with the full-dose of cyclosporine A. Unexpectedly, both FTY720 treatment arms were associated with lower creatinine clearance and higher incidence of macular edema. ${ }^{56,57}$ These results, unexplained but believed to be attributable to nonimmunological renal toxicity, indicated that FTY720 provided no benefit in comparison to standard care and resulted in temporary stopping of the development of FTY720 for renal transplantation.

The results of a randomized, placebo-controlled phase II study of FTY720 for RR MS have been recently published. ${ }^{58}$ In the trial, 281 patients were randomized to receive fingolimod ( 1.25 or $5 \mathrm{mg}$ orally/day) or a placebo. The primary outcome of the study was the total number of T1-W gadolinium-enhancing lesions at monthly intervals for 6 months. This cumulative number and the volume of gadolinium-enhanced lesions were significantly lower in the two treatment arms than in the placebo. Among the clinical endpoints considered, relapses observed in the treatment arms were approximately half those in the control group. This finding was appropriately reflected in the annualized relapse rates and other relapse-related measures. The number of patients remaining exacerbation-free was $86 \%$ in both treatment doses and $66 \%$ for the placebo control group. A 6-month extension of the core study showed a persisting effect on gadolinium-enhancing lesions in the patients who received continuous active treatment, and a significant decrease in those who switched from a placebo to the active drug. The study was not designed to address an effect on disability. Adverse events associated with fingolimod administration were upper respiratory tract infection, headache, diarrhea and nausea. There was one case of posterior reversible encephalopathy syndrome. Lymphopenia was, as expected, observed as a side effect. In addition, alanine aminotransferase increases of three of more times the upper limits of normal range occurred at significantly higher frequency in fingolimod-treated patients $(\sim 10 \%)$ than in placebo controls $(1 \%)$. Bradycardia and pulmonary function test abnormalities were also reported. The preliminary results of a further extension of the study to 24 additional months, which were presented at the American Neurological Association's 131st Annual Meeting, confirmed the published study in terms of side effects and clinical effects on MRI and relapse rate. Full results of a longterm clinical trial are being awaited to establish the potential of this agent as a treatment for MS. One theoretical safety, as well as efficacy concern that relates to the mode of action of FTY720, is whether the effects of 
the drugs on thymopoiesis will restrict the diversity of the naïve T-cell repertoire, an important feature of the immune system to be able to recognize pathogens as well as maintain immune tolerance. This could be particularly relevant in young subjects in whom the maintenance of immune repertoire is more reliant on thymic output. Indeed, FTY720 has been shown to preferentially deplete the naïve T-cell subsets, while not affecting memory/ effector $\mathrm{T}$ cells. ${ }^{59}$ Sequestration of lymphocytes in lymph nodes may require special precautions when the drug is discontinued so as to prevent exacerbations. Another aspect requiring elucidation is what the effect of FTY720 treatment will be on the potential for nervous tissue to undergo spontaneous or induced repair. In a rat model of spinal cord injury, S1P concentration was locally increased and contributed to the attraction of neural stem cells via the $\mathrm{S}_{1} \mathrm{P}_{1}$ receptor. ${ }^{60}$

At the present time, differences in study design, outcome measures and patient populations preclude comparing the efficacy of FTY720 with other disease-modifying agents. Two phase III studies in MS are currently ongoing. If the long-term administration of fingolimod is found to be safe and its efficacy is shown not to be inferior to the approved immunomodulatory agents, owing to its oral mode of administration, fingolimod could become a first-line treatment option, particularly in patients who do not wish to undertake or can not tolerate injectable treatments.

\section{MONOCLONAL ANTIBODIES}

Monoclonal antibodies (mAbs) are an emerging group of highly selective therapeutics that bind to a specific molecule expressed on the surface of targeted cells. ${ }^{61,62}$ The production of mAbs was first reported in 1975, and a decade later mAbs were studied as therapeutics for humans. Because the immunogenicity of nonhuman mAbs limited their repeated administration, current research focuses on development of chimeric, humanized and fully human mAbs. ${ }^{61,62}$ Chimeric mAbs consist typically of $\sim 33 \%$ of murine (variable region of the original mouse $\mathrm{Ab})$ and $67 \%$ of human $\left(\mathrm{F}_{\mathrm{c}}\right.$ domain) components (e.g., rituximab or basiliximab). In humanized mAbs, the murine component is further limited to 5 to $10 \%$ by engineering only hypervariable regions from a mouse antibodies $(\mathrm{Ab})$ into a human $\mathrm{Ab}(\mathrm{IgG})$ structure (e.g., daclizumab). Finally, fully human mAbs have $100 \%$ human structure and can be obtained from human cells or genetically-engineered mice (e.g., adalimumab). ${ }^{61,62}$

The outcome of the interaction between the mAb and its target depends on several characteristics:

1. The character, distribution and function of the targeted molecule, which will determine the cells that will be targeted and also the end result of the $\mathrm{mAb}$ binding to the specific cell type.

2. The properties of the mAb regarding the target molecule.

a. Binding $\mathrm{mAb}$ will deliver no signal to the targeted cell and neither will it prevent signaling through the molecule it binds. Binding mAbs will simply target a specific cell type, which may be consequently destroyed through several mechanisms outlined below (see "the effector functions of the mAbs"). Alternatively, binding mAb can be conjugated with a chemotherapeutic drug or a radioactive isotope.

b. Blocking mAb will block the interaction of the specific molecule with its ligand, without significant depletion of targeted cells. The example of blocking $\mathrm{mAb}$ is natalizumab or daclizumab.

c. Signaling $\mathrm{mAb}$ will deliver an intracellular signal, usually via oligomerization of the surface molecule (receptor) that it binds. The example of signaling $\mathrm{mAb}$ is muromonab (Orthoclone OKT3 [Ortho-Biotech Products, L.P., Bridgewater, NJ]).

3. The effector functions of mAb.

a. Complement-dependent cytotoxicity (CDC) - if the mAb binds and activates the $\mathrm{Clq}$ molecule of the complement system, the targeted cell may be killed through activation of the classical pathway of the complement that results in the formation of cytolytic membrane attack complex, which destroys the integrity of the cellular membrane. $\mathrm{Hu}$ man IgG4 lacks complement fixation and $\mathrm{IgG} 2$ is generally inefficient in complement activation; therefore these two IgG subtypes generally will not mediate significant CDC.

b. Antibody-dependent cellular cytotoxicity (ADCC) if the $\mathrm{mAb}$ binds $\mathrm{F}_{\mathrm{c}} \gamma$ receptors expressed on the surface of the immune cells capable of cytotoxicity (e.g., natural killer [NK] cells), targeted cells may be killed through the ADCC process.

c. Phagocytosis: If the mAb binds $F_{c} \gamma$ receptors on the surface of immune cells that are capable of phagocytosis (e.g., monocytes, macrophages, dendritic cells, B cells and neutrophils), targeted cells may be phagocytosed, or the interaction of the targeted cells with phagocytes may result in immunomodulation as a consequence of the activation of phagocytes. If $\mathrm{ADCC}$ and phagocytosis are important for the treatment effect of $\mathrm{mAb}$, then $\mathrm{F}_{\mathrm{c}} \gamma \mathrm{R}$ polymorphisms may underlie differences in therapeutic efficacy observed between patients (e.g., in the case of rituximab or alemtuzumab).

d. Half-life (or clearance rate): Half-life of the mAb and possibly also its transport across tissues is 
affected by its ability to bind to the neonatal $F_{c}$ receptor $\left(\mathrm{F}_{\mathrm{c}} \mathrm{Rn}\right){ }^{62}$

Clearly, the therapeutic effect, but also the side effect profile of mAbs will be highly dependent on all of the characteristics of $\mathrm{mAb} /$ target interactions previously outlined. Therefore, a detailed understanding of these characteristics as they apply to specific mAbs is necessary for our full appreciation of their mechanism of action.

There are several mAbs that were tested in MS, but they were found either to be ineffective or to cause serious adverse effects (e.g., anti-T12 [anti-CD6], anti-T11 [anti-CD2], OKT3 [anti-CD3], anti-T4 and cM-T412 [both anti-CD4], cA2 [anti-TNF- $\alpha$ ], Hu23F2G [anti-LFA-1], IDEC-131 [anti-CD154]), and their development was stopped. There are other mAbs that are in the early phases of clinical development (e.g., ATM-027 [anti-TCR V $35.2 /$ 5.3], CNTO 1275 and J695 [both anti-IL-12]) without available data on their potential efficacy in MS. The review of these agents is beyond the scope of the current article, but we refer the reader to the excellent and recently published review on this topic. ${ }^{63} \mathrm{We}$ have focused instead on reviewing those mAbs that have already proven their efficacy in MS, and are either available for clinical use or are in the later stages of clinical development and may reach our clinics in the foreseeable future.

\section{ALEMTUZUMAB (CAMPATH-1H; ANTI-CD52 AB)}

Alemtuzumab is humanized $\operatorname{IgG} 1 \kappa \mathrm{mAb}$ that binds glycoprotein CD52, which is expressed on the surface of $\mathrm{T}$ and B lymphocytes, NK cells, a majority of monocytes and macrophages, some granulocytes (but not neutrophils) and tissues of the male reproductive system. Binding of alemtuzumab to CD52 results in rapid (1 h) and prolonged (between 3-9 months, depending on cell type) depletion of targeted cells by CDC and ADCC mechanisms. As with other mAbs that cause cell depletion, alemtuzumab infusion is associated with an acute cytokine release syndrome, consisting of fever, headache, hypotension, malaise and urticaria. Because of this, alemtuzumab is usually administered in small repeated doses and patients are premedicated with high-dose steroids. Alemtuzumab is approved by the Food and Drug Administration (FDA) for the treatment of B-cell chronic lymphocytic leukemia, and currently available data on its therapeutic efficacy in MS originate from a single MS center (University of Cambridge, UK). ${ }^{64}$ Two observational treatment cohorts are reported in the literature: 1) the first one includes a total of 36 secondary-progressive (SP) MS patients with advanced disease (i.e., mean disease duration, 11.2 years with 3.6 years in progressive stage $)^{65,66}$ and the second represents 22 RR MS patients with highly active and early disease (mean disease du- ration, 2.7 years). ${ }^{64}$ Patients in both cohorts were selected based on a high exacerbation rate, recent progression of disability and persistent MRI inflammatory activity. Alemtuzumab $(100 \mathrm{mg})$ was administered as five daily doses (20 mg each) and patients were premedicated with solumedrol ( $1 \mathrm{~g}$ i.v.) on days 1 to 3 . Most of the RR MS patients (19 of 22) received elective retreatment after 12 to 18 months ( $20 \mathrm{mg} /$ day for 3 days). Alemtuzumab therapy led to a profound inhibition of new contrast-enhancing lesions (CEL) in both cohorts $(>90 \%$ for at least 18 months), and it also produced a significant decline $(>90 \%)$ in MS exacerbation rates. However, despite this strong effect on the inflammatory component of MS disease process, a majority of the SP MS patients continued to accumulate sustained disability in a progressive manner, although perhaps at a lower rate than before alemtuzumab therapy. ${ }^{64}$ MRI studies identified progressive axonal loss as a pathological substrate of ongoing disease progression in these patients (i.e., no significant increase in the proton density or T1-lesion volume, but progressive brain atrophy and decrease in $\mathrm{N}$-acetylaspartate/creatinine ratio on MR spectroscopy ${ }^{64}$ ). The rate of cerebral atrophy post-alemtuzumab therapy seemed to be greatest in patients with cerebral atrophy and high inflammatory lesion burden pretreatment. In contrast, RR MS patients treated with alemtuzumab experienced robust early improvement in their disability measures (by -1.2 EDSS points in 6 months post-treatment) and stabilization or even minor improvements in disability in the subsequent 2 years. Based on these data a randomized controlled trial of alemtuzumab versus interferon (IFN)- $\beta 1$ a (CAMMS223 trial) was initiated in 2003 and was recently reported (ECTRIMS 2006 and the Annual Meeting of the American Academy of Neurology [AAN], Boston, MA; 2007; S12.004) in which 334 treatment naïve RR MS patients were randomized 1:1:1 to receive IFN- $\beta 1 \mathrm{a}$ ( $44 \mu \mathrm{g} 3$ times/week), or a high dose of alemtuzumab $(24 \mathrm{mg} / \mathrm{d} \times 5 \mathrm{~d}$ i.v. at month 0 , and 24 $\mathrm{mg} / \mathrm{d} \times 3 \mathrm{~d}$ i.v. at month 12 ) or a low dose of alemtuzumab $(12 \mathrm{mg} / \mathrm{d} \times 5 \mathrm{~d}$ i.v. at month 0 , and $12 \mathrm{mg} / \mathrm{d} \times$ 3 d i.v. at month 12). The CAMMS223 trial also strove to answer the question of whether aggressive anti-inflammatory therapy applied very early in MS can prevent development of the neurodegenerative/progressive phase of MS. ${ }^{64}$ To this end, CAMMS223 enrolled RR MS patients with less than 3 years disease duration and EDSS 0 to 3.0 (inclusive) who experienced two or more attacks in the preceding 2 years and who had at least one contrast-enhancing lesion on a brain MRI. Alemtuzumab-treated patients (both doses) had $>75 \%$ reduction in relapse rate and $>65 \%$ reduction in the accumulation of sustained disability as compared to IFN- $\beta 1$ a-treated patients (both statistically significant). The significance of CAMMS223 trial, in our opinion, goes beyond simply confirming therapeutic efficacy of alemtuzumab in a con- 
trolled clinical trial. By using an active control arm (i.e., high-dose IFN- $\beta 1$ a) as opposed to a placebo arm, this trial clearly demonstrated that highly effective anti-inflammatory therapies can and should prove their superiority against currently available active immunomodulatory treatments.

Unfortunately, alemtuzumab therapy is associated with significant side effects. In addition to immediate cytokine release syndrome, alemtuzumab therapy of MS has been associated with increase in B-cell/Ab-mediated autoimmunity, specifically in immune thrombocytopenic purpura as seen in 6 of $216(2.8 \%)$ cases in CAMMS223 trial and in autoimmune thyroid disorders seen in 11 to $30 \%$ of treated MS patients (depending on the trial). Thyroid function tests and measurements of anti-thyroid stimulating hormone-receptor $\mathrm{Ab}$ and thyroid peroxidase $\mathrm{Ab}$ pretreatment may identify patients who are at high risk for the development of autoimmune thyroid disorders. Frequent screenings of complete blood counts are required to identify immune thrombocytopenic purpura cases and to institute appropriate therapy to prevent further morbidity or mortality.

The mechanism of action of alemtuzumab lies in rapid and seemingly complete depletion (at least from the peripheral blood) of CD52-bearing immune cells. The rate of cellular recovery differs among immune subpopulations: monocyte and B-cell numbers returned to baseline values by 3 months (and $B$ cell numbers often rose above the pretreatment baseline); CD8 $+\mathrm{T}$ cells recovered by approximately 30 months, whereas $\mathrm{CD} 4+\mathrm{T}$ cell recovery was approximately 61 months at last. ${ }^{64}$ It is not clear which of these immunological changes are responsible for the therapeutic effect of alemtuzumab, but it is interesting that the first repopulating CD4 $+\mathrm{T}$ cells are $\mathrm{CD} 25^{\text {bright }}$ and therefore may represent regulatory $\mathrm{T}$ cells. Another possible mechanism of action of alemtuzumab lies in the restoration of caspase- 3 expression in T cells, and hence their susceptibility to induction of apoptosis (Annual Meeting of AAN, Boston, MA 2007; P01.051).

In conclusion, alemtuzumab seems to be a powerful anti-inflammatory agent with efficacy on the immunemediated component of MS disease process that seemingly outperforms standard, currently available therapies. Unfortunately, this efficacy is associated with an increased risk of serious adverse events, and only careful evaluation of long-term data on alemtuzumab-treated patients will provide necessary information to guide the decision of whether the risk-benefit ratio of alemtuzumab therapy would justify its widespread use.

\section{DACLIZUMAB (ZENAPAX; ANTI-CD25 AB)}

Daclizumab is a humanized IgG1 mAb that blocks the IL-2-binding domain (i.e., Tac epitope) of the $\alpha$-chain of the IL-2 receptor (IL-2R). IL-2R is comprised of three subunits: $\alpha$-chain (CD25), which lack a signaling motif and two signaling chains: $\beta$ (CD122) and $\gamma(\mathrm{CD} 132)$. CD122 and CD132 together form an intermediate-affinity IL-2R, which binds IL-2 with $\mathrm{K}_{\mathrm{dis}} \sim 100 \mathrm{pM}$ and can deliver its signal intracellularly. When CD25 associates with CD122 and CD132, it increases the affinity of this complex for IL-2 by about 10 -fold; therefore, this trimolecular complex is called high-affinity IL-2R. CD25 is present at low levels in resting human $\mathrm{T}$ cells, but is significantly upregulated on activated $\mathrm{T}$ cells, enabling them to receive a high-affinity IL-2 signal. ${ }^{67}$ Because of the growth- and survival-promoting effect on $\mathrm{T}$ cells in vitro, the high-affinity IL-2 signal was believed to be crucial for the expansion and development of the effector functions of T cells. Therefore, it was postulated that the blockade of CD25 would result in selective functional inhibition of activated T cells. ${ }^{68}$ Indeed, it has been demonstrated that daclizumab (or the original murine anti-Tac $\mathrm{Ab}$ ) inhibits early IL-2R signal transduction events ${ }^{69,70}$ and blocks T-cell activation and expansion in vitro. ${ }^{71}$ Furthermore, daclizumab has proven its therapeutic efficacy in preventing rejection of different solid organ transplants (reviewed in Waldmann and O'Shea ${ }^{72}$ ). This putative mechanism of action served as a basis of therapeutic trials of daclizumab in autoimmune disorders, and the first therapeutic efficacy was demonstrated in the inflammatory uveitis. ${ }^{73,74}$ Two small, open-label (baseline versus treatment) phase II trials of daclizumab in MS have been published. ${ }^{75,76}$ Both targeted RR MS patients with inadequate clinical and paraclinical response (i.e., MRI) to IFN- $\beta$ preparations and used daclizumab as add-on therapy at the dose of $1 \mathrm{mg} / \mathrm{kg}$ of body weight administered as intravenous monthly infusions.

Daclizumab treatment led to a significant reduction $(\sim 70 \%)$ in the number and volume of CEL and to stabilization or improvements in clinical disability scores. ${ }^{75,76}$ Both the inhibition of brain inflammation by daclizumab and the reappearance of inflammation after cessation of the therapy developed gradually over a period of 2 to 3 months, suggesting that daclizumab induced gradual and prolonged immunomodulatory changes in vivo. A multicenter, randomized, doubleblinded phase II trial of daclizumab $(2 \mathrm{mg} / \mathrm{kg}$ s.c. every 2 weeks) in 230 RR MS patients with incomplete therapeutic response to IFN- $\beta$ (CHOICE trial) has been recently concluded. As news reports reflected (provided by Protein Design Labs, Inc and Biogen-IDEC), daclizumab add-on therapy led to a significant reduction in the number of new or enlarged CEL lesions on brain MRI at week 24 , as compared to the placebo.

We recently reported immunological studies supplementing the phase II NIH trial of daclizumab in MS. ${ }^{77}$ In contrast to the expected mechanism of action of daclizumab, we did not observe any significant inhibition of T-cell activation or function during in vivo administration of the drug. However, we did observe a 
profound and completely unexpected expansion of CD56 $6^{\text {bright }} \mathrm{NK}$ cells during daclizumab therapy, which correlated with the treatment outcome. CD56 $6^{\text {bright }} \mathrm{NK}$ cells represent a minute population of lymphocytes $(\sim 1 \%)$ in human peripheral blood. These cells have been labeled "immunoregulatory" because they are expanded under situations that assume immunoregulation, such as pregnancy or bone-marrow transplantation. In addition, CD56 $6^{\text {bright }} \mathrm{NK}$ cells home to lymph nodes and affect T-cell priming by production of cytokines and by killing of autologous immature dendritic cells. In our studies, we observed a slow but gradual decline in absolute numbers of CD4+ and CD8 $+\mathrm{T}$ cells during daclizumab therapy (by $\sim 10 \%$ ) and a statistically significant correlation between expansion of CD56 $6^{\text {bright }} \mathrm{NK}$ cells and reductions in T-cell numbers in vivo. Extensive in vitro experiments demonstrated that daclizumab-expanded CD56 ${ }^{\text {bright }}$ NK cells were capable of killing activated autologous $\mathrm{CD} 4+$ and $\mathrm{CD} 8+\mathrm{T}$ cells in a perforindependent manner. These data suggest an unexpected and novel mechanism of action of daclizumab via a regulatory circuit between innate and adaptive immune responses.

In conclusion, daclizumab represents a promising new immunomodulatory therapy of MS, with an intriguing mechanism of action. However, only large-scale, controlled clinical trials will be able to determine the extent of therapeutic efficacy and safety of this mAb in MS and other autoimmune disorders.

\section{NATALIZUMAB (TYSABRI; ANTI-VLA-4 AB)}

Natalizumab is a humanized $\operatorname{IgG} 4 \kappa \mathrm{mAb}$ that binds to the $\alpha_{4}$ subunit (CD49d) of $\alpha_{4} \beta_{1}$ (VLA-4) and $\alpha_{4} \beta_{7}$ integrins and prevents their interaction with their ligands. Because of its $\operatorname{IgG} 4 \kappa$ frame, natalizumab does not induce CDC. The $\alpha_{4}$ integrin subunit is expressed on most leukocytes, with the exception of neutrophils. VLA-4 interaction with vascular cell adhesion molecule-1 is a prerequisite for transmigration of immune cells across the blood-brain barrier (BBB), whereas $\alpha_{4} \beta_{7}$ integrin interaction with the mucosal addressin cell adhesion molecule (MadCAM) mediated migration of gut-homing T cells. In addition, the interaction of $\alpha_{4} \beta_{1}$ integrin with the extracellular matrix proteins fibronectin, osteopontin and thrombospondin may modulate the activation and survival of leukocytes that entered CNS parenchyma, thus perpetuating the inflammatory cascade associated with MS. $^{78}$

The clinical efficacy of natalizumab in MS has been studied in three phase II trials ${ }^{79-81}$ and two phase III trials. ${ }^{82,83}$ All of the clinical trials demonstrated efficacy of natalizumab on the inhibition of brain inflammatory activity as measured by the CEL on a brain MRI. When used as a single-dose therapy for acute clinical relapse (symptoms lasting $>24$ but $<96$ hours), natalizumab did not accelerate clinical recovery, although it did lead to a significant decrease in the volume of CEL as compared to a placebo 1 to 3 weeks after administration. ${ }^{81}$

Early phase II trial with prolonged dosing of natalizumab raised a possibility that cessation of natalizumab therapy may lead to an increase in relapse rate (rebound phenomenon). ${ }^{79}$ However, this observation was not confirmed in large phase III studies. ${ }^{82,83}$ The dose-finding phase II study indicated that $3 \mathrm{mg} / \mathrm{kg}$ and $6 \mathrm{mg} / \mathrm{kg}$ dosing had comparable efficacy ${ }^{80}$ and therefore a standard dose of $300 \mathrm{mg} / \mathrm{month}$ was selected for both phase III trials. In the monotherapy AFFIRM trial that enrolled RR MS patients with clinically active MS, natalizumab reduced the risk of sustained progression of disability by $42 \%$ for a two-year timespan as compared to a placebo ( $\mathrm{p}<$ $0.001){ }^{82}$ It reduced the rate of clinical relapses by $68 \%$, development of CEL by $92 \%$ and new or enlarging T2 weighted image lesions by $83 \%$ (all $\mathrm{p}<0.001$ ). These are clearly the best efficacy results obtained by an immunomodulatory agent in any phase III clinical trial for active inflammatory RR MS to date. However, because the therapeutic efficacy results are dependent on the trial design and the performance of the placebo group, it would be premature to directly presume therapeutic superiority of natalizumab in comparison with all available disease-modifying therapies for MS. In the Safety and Efficacy of Natalizumab in Combination with Interferon Beta-1a in Patients with Relapsing Remitting Multiple Sclerosis (SENTINEL) trial, the combination of natalizumab with IFN- $\beta 1$ a (Avonex [Biogen Idec, Boston, MA], $30 \mu \mathrm{g}$ intramuscular weekly) achieved $24 \%$ reduction of the risk of sustained progression of disability as compared to IFN- $\beta 1$ a alone $(p=0.02){ }^{83}$ It reduced the rate of clinical relapses by $55 \%$, development of CEL by $89 \%$ and new or enlarging T2 weighted image lesions by $83 \%$ (all $\mathrm{p}=0.001$ ). Although the inclusion criteria in regard to MS disease activity were identical between the AFFIRM and SENTINEL trials, and consequently the mean EDSS scores in the population of patients enrolled were comparable $(2.3+/-1.2$ vs $2.4+/-1.1)$, natalizumab had apparently almost twice the pronounced effect on the sustained progression of disability in the AFFIRM trial as compared to the SENTINEL trial (42\% vs $24 \%$ reduction of progression of disability in two years). Because the placebo arm in the AFFIRM trial and IFN- $\beta 1 \mathrm{a}$ arm in the SENTINEL trial accumulated disability at virtually identical rates (29\% of patients had progression of disability develop in two years), and because IFN- $\beta 1$ a has been shown to reduce accumulation of sustained disability in previous trials,${ }^{84}$ it is likely that the two cohorts differed in their baseline rate of accumulation of disability. From this standpoint it is interesting to observe that patients enrolled in the SENTINEL 
trial were slightly older $(38.9 \pm 7.7$ vs $36.0 \pm 8.3$ years $)$ and had a longer disease duration (7.0 vs 5.0 years), as compared to patients in the AFFIRM trial. These data suggest that natalizumab, as with other therapeutic agents that solely target the inflammatory component of the MS disease process, will likely have much less of a pronounced effect on the accumulation of clinical disability in older patients with longer disease duration, which is believed to be predominantly sustained by noninflammatory (i.e., neurodegenerative) mechanisms. However, this notion will need to be investigated in future clinical trials.

Natalizumab was well tolerated, and the rate of all infectious complications was similar between the natalizumab and the control group, although natalizumab patients experienced a slightly increased risk of serious infectious complications such as pneumonia, urosepsis and in the SENTINEL trial, progressive multifocal leukoencephalopathy (PML). ${ }^{82,83}$ The risk of PML with natalizumab therapy was subsequently estimated to be approximately 1 in 1000 patients treated for a mean of 17.9 months. ${ }^{85}$ The incidence of cancer was too low in both trials to draw any meaningful conclusions, and this issue needs to be watched in post-marketing surveillance. Natalizumab-treated patients experienced more infusion reactions and hypersensitivity reactions (including $0.8 \%$ of anaphylactoid reactions) than control patients. Six percent of natalizumab-treated patients developed persistent antibodies to natalizumab, which resulted in a loss of efficacy and an increase in infusion adverse events. $^{82,83}$

As expected from its putative mechanism of action (i.e., blocking transmigration of leukocytes to the CNS and possibly also to the gut), lymphocyte, monocyte, basophil and eosinophil, but not neutrophil, counts in the peripheral blood increased in natalizumab-treated patients by 50 to $60 \%$ compared to the placebo; however, the mean counts generally remained within the normal range. ${ }^{79,80,82,83}$ In vitro immunological studies demonstrated that natalizumab treatment resulted in approximately $40 \%$ inhibition of migration of peripheral blood mononuclear cells across fibronectin-coated Boyden chambers. ${ }^{86}$ Stuve et al ${ }^{87}$ quantified CSF pleocytosis in natalizumab-treated MS patients (after a median of 30 doses) and in controls, which included both untreated MS patients and other noninflammatory neurological disease controls. The numbers of white blood cells, CD4 + and CD8 $+\mathrm{T}$ cells, B cells and plasma cells in CSF were significantly lower in natalizumab-treated MS patients as compared with other noninflammatory neurological disease controls, whereas untreated MS patients had significantly higher frequency of all these immune cell subtypes. This robust difference persisted even 6 months after cessation of natalizumab therapy. The authors inter- preted their results as evidence that natalizumab treatment results in a significant and unexpectedly longlasting (6-month) decrease in all major lymphocyte subsets in the CSF. ${ }^{87}$ However, there are several limitations of this study that warrant caution in the interpretation of its results: 1) natalizumab-treated and untreated MS cohorts apparently differed in their demographic characteristics, although no statistics are provided in the article; 2) these two cohorts were mostly collected at different institutions by different investigators and 3 ) the authors did not provide any details about the relationship between the times of CSF collection in the untreated MS patients to their MS clinical activity (i.e., relapses). Because of this, it is unclear if the untreated and natalizumab- treated MS cohorts in this article are directly comparable, and the definite acceptance of the conclusions from this study would require analysis of the CSF samples collected in the same patient cohort before and after natalizumab therapy, similar to the analysis performed in rituximab-treated MS patients. ${ }^{88,89}$ This is a very important issue, because if the in vivo effect of natalizumab on leukocyte transmigration across the $\mathrm{BBB}$ is as profound, as suggested by Stuve et al., ${ }^{87}$ and lasts more than 6 months, then one could postulate that less frequent dosing of natalizumab may be sufficient for its therapeutic efficacy and that a simple cessation of natalizumab therapy in the case of the development of PML would be unlikely to restore immune surveillance of the brain for the following 6 months. Because the immunological study by Niino et al. ${ }^{86}$ implies a much less profound effect of natalizumab on the inhibition of leukocyte trafficking, and this observation is supported by the MRI study evaluating the effect of natalizumab therapy on subtle BBB leakage within visibly nonenhancing MS lesions, ${ }^{90}$ a longitudinal study evaluating leukocyte subtypes in the CSF of MS patients before and after natalizumab therapy is needed to provide definitive answers on the magnitude and duration of the inhibitory effect of natalizumab on CNS immuno-surveillance. Interestingly, a follow-up study by Stuve et al. ${ }^{91}$ demonstrated that natalizumab therapy leads to a decrease in CSF CD4+/CD8 + Tcell ratio to the levels that are comparable with those observed in the CSF of patients with AIDS. ${ }^{91}$ This observation is intriguing and has implications in regard to the development of PML in natalizumabtreated patients.

In conclusion, natalizumab seems to be the most potent FDA-approved immunomodulatory agent that we have currently available for the treatment of active inflammatory MS. Long-term, follow-up studies and postmarketing surveillance will be important in determining true risk-benefit ratio associated with the long-term natalizumab monotherapy in MS. 


\section{RITUXIMAB (RITUXAN OR MABTHERA; ANTI-CD20 AB)}

Rituximab is a chimeric murine/human $\operatorname{IgG}_{1} \kappa \mathrm{mAb}$ directed against CD20. CD20 is B-lymphocyte restricted differentiation antigen, which is expressed on pre-B cells and mature B cells, but not on differentiated plasma cells or any other cell type. ${ }^{92} \mathrm{CD} 20$ functions as B cell $\mathrm{Ca}^{2+}$ channel and it regulates cell cycle progression. ${ }^{93} \mathrm{CD} 20$ / rituximab complex is not internalized. Instead, the CD20-expressing B cells are killed after rituximab binding, most likely through CDC and ADCC mechanisms, resulting in rapid (within 2 weeks) and sustained (6-9 months) depletion of circulating B cells. B cell recovery begins approximately 6 months after treatment and returns to normal levels by 12 months after treatment. Reduction of $\mathrm{B}$ cells decreases de novo Ab production and a majority of treated patients developed mild reductions develop in both IgM and IgG serum levels (observed 5-11 months post-treatment), which only rarely resulted in values below the normal range. ${ }^{94}$

Rituximab therapy (monotherapy or add-on therapy) resulted in a statistically significant reduction of inflammation in several autoimmune disorders, including rheumatoid arthritis, systemic lupus erythematosus and immune thrombocytopenic purpura. ${ }^{92}$ The mechanism of action of rituximab in these disorders does not seem to be entirely explained by the depletion of B cells. Although it is postulated that depletion of B cells results in a decline in the number of antigen-presenting cells and a decline in de novo production of auto- $\mathrm{Ab}$, rituximab treatment resulted in reductions of global biologic markers of inflammation (e.g., IL-6, C-reactive protein, serum amyloid protein or anti-citrullinated peptide in rheumatoid factor). A novel and provoking hypothesis was recently suggested to explain these findings (i.e., the immune complex decoy hypothesis). ${ }^{95}$ According to this hypothesis, binding of thousands of rituximab-B cell complexes attract and bind $\mathrm{F}_{\mathrm{c}} \gamma \mathrm{R}$-expressing cells (e.g., monocytes, macrophages, NK cells, DC, and neutrophils) that diminish their recruitment into inflammatory sites with resulting limitation of tissue damage. Indeed, genetic polymorphism of $\mathrm{F}_{\mathrm{c}} \gamma \mathrm{R}$ (specifically Fc $\gamma \mathrm{RIIIa}-$ $158 \mathrm{~V}$ vs Fc $\gamma$ RIIIa- $158 \mathrm{~F}$ genetic dimorphism), which influences the affinity of $F_{c} \gamma R$ binding to human IgG, has been shown to influence therapeutic response to rituximab. ${ }^{92}$ Although this hypothesis is intriguing, it requires full investigation before it can be accepted.

Rituximab is generally well tolerated by most patients. The majority of adverse events are infusion related. The most severe manifestations include acute respiratory distress syndrome, myocardial infarction, cardiogenic shock and anaphylactic shock. In rare cases the outcome may be fatal. When used for therapy of lymphomas and leukemias, tumor lysis syndrome consisting of acute renal failure, hyperkalemia, hypocalcemia and hyperuricemia have been reported within 12 to 24 hours after rituximab infusion. Administration of rituximab could also result in severe mucocutaneous reactions with an onset of 1 to 13 weeks post-infusion. Two cases of PML have been recently reported with rituximab use in systemic lupus erythematosus. Patients treated with rituximab should avoid immunizations with live virus vaccines.

Several small scale studies (phase I/II and case reports) of rituximab in MS have been published ${ }^{88}$ and others are currently in progress (Annual Meeting of AAN, Boston, MA 2007; S02.001 and S12.003). The largest of the published studies is a phase II trial of rituximab add-on therapy in 16 RR MS patients with inadequate therapeutic response to FDA-approved immunomodulatory medications. ${ }^{88}$ Rituximab therapy (375 $\mathrm{mg} / \mathrm{m}^{2}$ weekly $\times 4$ ) resulted in a significant decline in the number of CSF B cells (by 90\%), and also of CSF T cells (by 55\%) 24 weeks after the initial dose of rituximab. As expected, the number of oligoclonal bands, CSF IgG concentration and CSF IgG synthesis rate were not affected by the treatment. The effect on serum $\mathrm{Ab}$ levels (IgM and $\operatorname{IgG}$ ) against myelin oligodendrocyte glycoprotein or myelin basic protein were not significantly altered by therapy, although in some patients mild decline was noted. Similarly, rituximab exerted no consistent effect on neutralizing $\mathrm{Ab}$ against IFN- $\beta$ and, in fact, this therapy resulted in de novo formation of neutralizing $\mathrm{Ab}$ in some research subjects. The treatment was well-tolerated and patients remained clinically stable during the trial. The primary outcome measure, defined as a change in the CEL on a brain MRI, was not reported in this study. The CSF findings of this trial are in agreement with the previously published case report of use of rituximab in a single RR MS patient with rapidly progressive disease course and suboptimal therapeutic response to FDA-approved immunomodulatory therapies, including mitoxantrone. ${ }^{89}$ The authors of this study also observed complete and prolonged (4 months after the last rituximab dose) depletion of B cells from the CSF of the treated patient. In addition, administration of rituximab ( $1 \mathrm{~g}$ i.v. every 4 weeks $\times 3$ doses) led to the inhibition of CEL and clinical stabilization of the disease progression in this patient for the 4 months after treatment. In contrast with complete depletion of CSF B cells observed in RR MS patients, only incomplete depletion of CSF B cells was observed in the small study involving four PP-MS patients treated with rituximab $\left(375 \mathrm{mg} / \mathrm{m}^{2}\right.$ weekly $\times 4) .{ }^{96}$ These authors also observed a rebound in the numbers of CSF B cells 14 to 20 months after rituximab treatment, which exceeded pretreatment B-cell numbers two- to nine-fold. However, rituximab also temporarily (for less than 14 months) suppressed the activation state of $\mathrm{B}$ cells in the CSF. ${ }^{96} \mathrm{~A}$ phase II, randomized placebo-controlled clinical trial of rituximab in 104 
RR-MS patients has been recently concluded and reported (Annual Meeting of AAN, Boston, MA 2007; S12.003). Rituximab therapy $(1000 \mathrm{mg}$ i.v. $\times 2)$ caused significant reduction in CEL at weeks 12, 16, 20 and 24 post-infusion, confirming its immunomodulatory role in RR MS.

In conclusion, rituximab has established itself as an emerging therapy for autoimmunity and deserves full evaluation of its therapeutic potential in MS. Although originally considered as a specific treatment for Ab-mediated immune disorders such as neuromyelitis optica and Ab-mediated pathological subtypes of MS, if the immune complex decoy hypothesis previously discussed proves to be correct, the indications for rituximab therapy may broaden to other MS subtypes. The limited published data suggest that alterations in the BBB may be required for effective and prolonged depletion of $\mathrm{B}$ cells from the CSF, and observed rebound in CSF B cell numbers may indicate the need for repeated dosing. However, it is unclear if CSF B-cell depletion correlates with the therapeutic effect of rituximab. Therefore, only follow-up studies performed in patients with high- versus low-inflammatory MS (including PP MS patients) will be able to provide definitive answers about the potential effectiveness of rituximab therapy in different MS subgroups. Similarly to natalizumab, case reports of PML after rituximab therapy raise concerns about its longterm administration.

\section{REMYELINATING ANTIBODIES}

Although all of the currently available therapies of MS act by modulating immune responses, it is becoming exceedingly clear that such treatment strategies provide only limited (if any) beneficial effect on already accumulated CNS pathology. Although oligodendrocytes and their precursors are present in MS lesions, ${ }^{97}$ the remyelination and repair of demyelinated MS lesions is at best partial and may be limited only to some MS subtypes. ${ }^{98}$ Because chronically demyelinated axons may degenerate,${ }^{99}$ thus perpetuating irreversible damage associated with MS, therapies that promote remyelination and repair are critically needed. One such strategy resides in the utilization of remyelination-promoting $\mathrm{Ab} .{ }^{100}$ The search for remyelinating $\mathrm{Ab}$ was initiated by the observation in 1990 that polyclonal IgG from the serum of mice immunized with spinal cord homogenate significantly enhanced remyelination in the Theiler's viral model of MS. ${ }^{101}$ Since then, many follow-up studies demonstrated that human polyclonal IgG (i.e., commercially available as IVIg preparations collected from thousands of healthy donors) can also have the same remyelination-enhancing potential in animal models. Based on these observations, several clinical trials evaluated the regenerative potential of IVIg, ${ }^{102-105}$ and all of them were unsuccessful in demonstrating any beneficial effect of this therapy on enhanced recovery from targeted neurological deficit (reviewed in reference ${ }^{106}$ ). However, the administration of IVIg in SP MS patients (European Study on Intravenous Immunoglobulin in Secondary Progressive Multiple Sclerosis [ESIMS], IVIg $1 \mathrm{mg} / \mathrm{kg}$ monthly $\times 27$ months) was associated with less rapid decline in brain volume (partial cerebral fraction $-0.62 \pm 0.88 \%$ vs $-0.88 \pm$ $0.91 \% ; \mathrm{p}=0.009$ ) as compared to placebo group. ${ }^{100}$ Although no plausible explanation was provided by these studies to explain the discrepant efficacy of IVIg in MS versus animal models of demyelination, encouraging MRI data from the ESIMS suggests that remyelinationpromoting potential of IVIg in MS is at best mild to modest and requires prolonged administration of treatment. In the meantime, the basic research studies indicated that polyclonal IgM is significantly more effective in promoting remyelination than polyclonal $\mathrm{IgG}$ preparations. ${ }^{107,108}$ In addition, both mouse and human remyelination-promoting monoclonal $\mathrm{IgM} \mathrm{Ab}$ were identified, and they all share the common feature of the ability to bind oligodendrocytes in vitro. However, binding oligodendrocytes in vitro is a necessary, but not sufficient prerequisite for remyelinating capacity of the $\mathrm{Ab} .{ }^{109}$ One of the identified remyelination-promoting human IgM $\mathrm{Ab}$, sHIgM22, is currently being developed for therapeutic trial in humans. The mechanism by which these mAbs promote remyelination is not clear, but sHIgM22 provides an activation signal to oligodendrocytes, demonstrated by increased intracellular $\mathrm{Ca}^{2+}$ concentration after binding sHIgM22 in vitro. In addition, sHIgM22 enters brain parenchyma ${ }^{108}$ and is therapeutically active in minute quantities. ${ }^{110}$ The complement-binding ability of this $\mathrm{Ab}$ is not required for its remyelination-promoting potential, because the $\mathrm{F}_{\mathrm{ab}}$ portion of the sHIgM22 retains its efficacy. ${ }^{111}$ Nevertheless, it remains unclear if other remyelination-promoting $\mathrm{Ab}$ have the same putative mechanism of action or similar biological properties as sHIgM22.

Clearly, understanding the mechanism by which oligodendrocyte-binding $\mathrm{Ab}$ may promote remyelination and repair is crucially important for development of therapeutic strategies that enhance remyelination in MS. The use of sHIgM22 in a proof-of-principle clinical trial will be extremely important to determine if demyelination associated with MS is unique in comparison to animal models of CNS demyelination, and whether sHIgM22 is capable of overcoming an apparent block in effective remyelination that has been postulated in MS. ${ }^{97}$

\section{CONCLUSIONS}

Hematopoietic stem cell transplantation and high-dose cyclophosphamide alone aim to restore immune tolerance by exploiting intensive immune suppression and the 
powerful homeostatic signals that originate from it and result in immune regeneration. In contrast, specific pharmacological agents aim to achieve immune tolerance through selective, continuous or cyclic modulation of immune function. Fingolimod prevents egress of lymphocytes from lymphoid organs resulting in their sequestration. Monoclonal antibodies represent a rapidly expanding category of therapeutics that can selectively target single molecules or cell types but often exert multifarious actions. They have already proven to be exceptionally effective therapeutic modalities targeting different proposed mechanisms of MS pathophysiology. We believe that their development will significantly expand the armamentarium of therapeutics that will be available to MS clinicians in the near future. In addition, by correlating the effectiveness of $\mathrm{mAb}$ on MS clinical outcomes with their effect on the function of immune system and CNS, they will allow us to better understand the pathophysiology of MS and decipher the mechanisms that underlie MS disease heterogeneity. Hopefully this gain in knowledge will translate into development of even more powerful and safer therapeutics for all clinical and pathological MS subtypes.

\section{REFERENCES}

1. Mezey E, Key S, Vogelsang G, Szalayova I, Lange GD, Crain B. Transplanted bone marrow generates new neurons in human brains. Proc Natl Acad Sci U S A 2003;100:1364-1369.

2. Mezey E, Chandross KJ, Harta G, Maki RA, McKercher SR. Turning blood into brain: cells bearing neuronal antigens generated in vivo from bone marrow. Science 2000;290:1779-1782.

3. Weimann JM, Charlton CA, Brazelton TR, Hackman RC, Blau HM. Contribution of transplanted bone marrow cells to Purkinje neurons in human adult brains. Proc Natl Acad Sci U S A 2003; 100:2088-2093.

4. Castro RF, Jackson KA, Goodell MA, Robertson CS, Liu H, Shine HD. Failure of bone marrow cells to transdifferentiate into neural cells in vivo. Science 2002;297:1299.

5. Wagers AJ, Sherwood RI, Christensen JL, Weissman IL. Little evidence for developmental plasticity of adult hematopoietic stem cells. Science 2002;297:2256-2259.

6. Karussis DM, Vourka-Karussis U, Lehmann D, et al. Prevention and reversal of adoptively transferred, chronic relapsing experimental autoimmune encephalomyelitis with a single high dose cytoreductive treatment followed by syngeneic bone marrow transplantation. J Clin Invest 1993;92:765-772.

7. Burt RK, Padilla J, Begolka WS, Canto MC, Miller SD. Effect of disease stage on clinical outcome after syngeneic bone marrow transplantation for relapsing experimental autoimmune encephalomyelitis. Blood 1998;91:2609-2616.

8. Griffith LM, Pavletic SZ, Tyndall A, et al. Feasibility of allogeneic hematopoietic stem cell transplantation for autoimmune disease: position statement from a National Institute of Allergy and Infectious Diseases and National Cancer Institute-Sponsored International Workshop, Bethesda, MD, March 12 and 13, 2005. Biol Blood Marrow Transplant 2005;11:862-870.

9. McAllister LD, Beatty PG, Rose J. Allogeneic bone marrow transplant for chronic myelogenous leukemia in a patient with multiple sclerosis. Bone Marrow Transplant 1997;19:395-397.

10. Muraro PA, Douek DC, Packer A, et al. Thymic output generates a new and diverse TCR repertoire after autologous stem cell transplantation in multiple sclerosis patients. J Exp Med 2005; 201:805-816.

11. Muraro PA, Douek DC. Renewing the T cell repertoire to arrest autoimmune aggression. Trends Immunol 2006;27:61-67.
12. de Kleer I, Vastert B, Klein M, et al. Autologous stem cell transplantation for autoimmunity induces immunologic selftolerance by reprogramming autoreactive T-cells and restoring the CD4+CD25+ immune regulatory network. Blood 2005;1:1.

13. McSweeney P, Pasquini MC, Krukeia M, et al. Hematopoietic stem cell transplantation (HCT) for autoimmune diseases (AI): review of transplants performed in North and South America and reported to the Center for International Blood and Marrow Transplantation (CIBMTR). Biol Blood Marrow Transplant 2007; 13:34.

14. Saccardi R, Kozak T, Bocelli-Tyndall C, et al. Autologous stem cell transplantation for progressive multiple sclerosis: update of the European group for blood and marrow transplantation auto immune diseases working party database. Mult Scler 2006;12:110.

15. Fassas A, Anagnostopoulos A, Kazis A, et al. Autologous stem cell transplantation in progressive multiple sclerosis-an interim analysis of efficacy. J Clin Immunol 2000;20:24-30.

16. Nash RA, Bowen JD, McSweeney PA, et al. High-dose immunosuppressive therapy and autologous peripheral blood stem cell transplantation for severe multiple sclerosis. Blood 2003;102: $2364-2372$.

17. Burt RK, Cohen BA, Russell E, et al. Hematopoietic stem cell transplantation for progressive multiple sclerosis: failure of a total body irradiation-based conditioning regimen to prevent disease progression in patients with high disability scores. Blood 2003; 102:2373-2378.

18. Saiz A, Blanco Y, Carreras E, et al. Clinical and MRI outcome after autologous hematopoietic stem cell transplantation in MS Neurology 2004;62:282-284.

19. Saccardi R, Mancardi GL, Solari A, et al. Autologous HSCT for severe progressive multiple sclerosis in a multicenter trial: impact on disease activity and quality of life. Blood 2005;105:26012607.

20. Ni XS, Ouyang J, Zhu WH, Wang C, Chen B. Autologous hematopoietic stem cell transplantation for progressive multiple sclerosis: report of efficacy and safety at three yr of follow up in 21 patients. Clin Transplant 2006;20:485-489.

21. Samijn JP, te Boekhorst PA, Mondria T, et al. Intense $T$ cell depletion followed by autologous bone marrow transplantation for severe multiple sclerosis. J Neurol Neurosurg Psychiatry 2006;77:46-50.

22. Mancardi GL, Saccardi R, Filippi M, et al. Autologous hematopoietic stem cell transplantation suppresses Gd-enhanced MRI activity in MS. Neurology 2001;57:62-68.

23. Saiz A, Carreras E, Berenguer J, et al. MRI and CSF oligoclonal bands after autologous hematopoietic stem cell transplantation in MS. Neurology 2001;56:1084-1089.

24. Inglese M, Mancardi GL, Pagani E, et al. Brain tissue loss occurs after suppression of enhancement in patients with multiple sclerosis treated with autologous haematopoietic stem cell transplantation. J Neurol Neurosurg Psychiatry 2004;75:643-644.

25. Chen JT, Collins DL, Atkins HL, Freedman MS, Galal A, Arnold DL. Brain atrophy after immunoablation and stem cell transplantation in multiple sclerosis. Neurology 2006;66:1935-1937.

26. Roccatagliata L, Rocca MA, Valsasina $P$, et al. The long-term effect of AHSCT on MRI measures of MS evolution: a five-year follow-up study. Mult Scler 2007 Apr 27; [Epub ahead of print].

27. Coles AJ, Cox A, Le Page E, et al. The window of therapeutic opportunity in multiple sclerosis: evidence from monoclonal antibody therapy. J Neurol 2005;27:27.

28. Metz I, Lucchinetti CF, Openshaw H, et al. Multiple sclerosis pathology after autologous stem cell transplantation: ongoing demyelination and neurodegeneration despite suppressed inflammation. Mult Scler 2006;12:S9.

29. Cassiani-Ingoni R, Muraro PA, Magnus T, et al. Disease progression after bone marrow transplantation in a model of multiple sclerosis is associated with chronic microglial and glial progenitor response. J Neurol Exp Neuropathol 2007;66:637-649.

30. Comi G, Kappos L, Clanet M, et al. Guidelines for autologous blood and marrow stem cell transplantation in multiple sclerosis: a consensus report written on behalf of the European Group for Blood 
and Marrow Transplantation and the European Charcot Foundation. BMT-MS Study Group. J Neurol 2000;247:376-382.

31. Bergamaschi R. Prognosis of multiple sclerosis: clinical factors predicting the late evolution for an early treatment decision. Expert Rev Neurother 2006;6:357-364.

32. Bielekova B, Kadom N, Fisher E, et al. MRI as a marker for disease heterogeneity in multiple sclerosis. Neurology 2005;65: 1071-1076.

33. Portaccio E, Amato MP, Siracusa G, et al. Autologous hematopoietic stem cell transplantation for very active relapsing-remitting multiple sclerosis: report of two cases. Mult Scler 2007;13: 676-678.

34. Brodsky RA, Petri M, Smith BD, et al. Immunoablative high-dose cyclophosphamide without stem-cell rescue for refractory, severe autoimmune disease. Ann Intern Med 1998;129:1031-1035.

35. Weiner HL, Cohen JA. Treatment of multiple sclerosis with cyclophosphamide: critical review of clinical and immunologic effects. Mult Scler 2002;8:142-154.

36. Karni A, Balashov K, Hancock WW, et al. Cyclophosphamide modulates CD4 $+\mathrm{T}$ cells into a $\mathrm{T}$ helper type 2 phenotype and reverses increased IFN-gamma production of CD8 $+\mathrm{T}$ cells in secondary progressive multiple sclerosis. J Neuroimmunol 2004; 146:189-198

37. Gladstone DE, Zamkoff KW, Krupp L, et al. High-dose cyclophosphamide for moderate to severe refractory multiple sclerosis. Arch Neurol 2006;63:1388-1393.

38. Fujita T, Inoue K, Yamamoto S, et al. Fungal metabolites. Part 11. A potent immunosuppressive activity found in Isaria sinclairii metabolite. J Antibiot (Tokyo) 1994;47:208-215.

39. Brinkmann V, Davis MD, Heise CE, et al. The immune modulator FTY720 targets sphingosine 1-phosphate receptors. J Biol Chem 2002;277:21453-21457.

40. Matloubian M, Lo CG, Cinamon G, et al. Lymphocyte egress from thymus and peripheral lymphoid organs is dependent on S1P receptor 1. Nature 2004;427:355-360.

41. Maeda Y, Matsuyuki H, Shimano K, Kataoka H, Sugahara K, Chiba K. Migration of CD4 T cells and dendritic cells toward sphingosine 1-phosphate (S1P) is mediated by different receptor subtypes: S1P regulates the functions of murine mature dendritic cells via S1P receptor type 3. J Immunol 2007;178:3437-3446.

42. Idzko M, Panther E, Corinti S, et al. Sphingosine 1-phosphate induces chemotaxis of immature and modulates cytokine-release in mature human dendritic cells for emergence of Th2 immune responses. Faseb J 2002;16:625-627.

43. Muller H, Hofer S, Kaneider N, et al. The immunomodulator FTY720 interferes with effector functions of human monocytederived dendritic cells. Eur J Immunol 2005;35:533-545.

44. Idzko M, Hammad $\mathrm{H}$, van Nimwegen $\mathrm{M}$, et al. Local application of FTY720 to the lung abrogates experimental asthma by altering dendritic cell function. J Clin Invest 2006;116:2935-2944.

45. Chiba K, Matsuyuki H, Maeda Y, Sugahara K. Role of sphingosine 1-phosphate receptor type 1 in lymphocyte egress from secondary lymphoid tissues and thymus. Cell Mol Immunol 2006; 3:11-19.

46. Fujino M, Funeshima N, Kitazawa Y, et al. Amelioration of experimental autoimmune encephalomyelitis in Lewis rats by FTY720 treatment. J Pharmacol Exp Ther 2003;305:70-77.

47. Kataoka H, Sugahara K, Shimano K, et al. FTY720, sphingosine 1-phosphate receptor modulator, ameliorates experimental autoimmune encephalomyelitis by inhibition of $\mathrm{T}$ cell infiltration. Cell Mol Immunol 2005;2:439-448.

48. Webb M, Tham CS, Lin FF, et al. Sphingosine 1-phosphate receptor agonists attenuate relapsing-remitting experimental autoimmune encephalitis in SJL mice. J Neuroimmunol 2004;153: $108-121$.

49. Payne SG, Oskeritzian CA, Griffiths R, et al. The immunosuppressant drug FTY720 inhibits cytosolic phospholipase A2 independently of sphingosine-1-phosphate receptors. Blood 2007;109:10771085.

50. Daniel C, Sartory N, Zahn N, Geisslinger G, Radeke HH, Stein JM. FTY720 ameliorates Th1-mediated colitis in mice by directly affecting the functional activity of $\mathrm{CD} 4+\mathrm{CD} 25+$ regulatory $\mathrm{T}$ cells. J Immunol 2007;178:2458-2468.
51. Liao JJ, Huang MC, Goetzl EJ. Cutting edge: alternative signaling of TH17 cell development by sphingosine 1-phosphate. J Immunol 2007;178:5425-5428.

52. Osinde M, Mullershausen F, Dev KK. Phosphorylated FTY720 stimulates ERK phosphorylation in astrocytes via S1P receptors. Neuropharmacology 2007;52:1210-1218.

53. Mullershausen F, Craveiro LM, Shin Y, et al. Phosphorylated FTY720 promotes astrocyte migration through sphingosine-1phosphate receptors. J Neurochem 2007.

54. Novgorodov AS, El-Alwani M, Bielawski J, Obeid LM, Gudz TI Activation of sphingosine-1-phosphate receptor S1P5 inhibits oligodendrocyte progenitor migration. Faseb J 2007;21:1503-1514.

55. Budde K, Schutz M, Glander P, et al. FTY720 (fingolimod) in renal transplantation. Clin Transplant 2006;20(suppl 17):17-24.

56. Tedesco-Silva H, Pescovitz MD, Cibrik D, et al. Randomized controlled trial of FTY720 versus MMF in de novo renal transplantation. Transplantation 2006;82:1689-1697.

57. Salvadori M, Budde K, Charpentier B, et al. FTY720 versus MMF with cyclosporine in de novo renal transplantation: a 1-year, randomized controlled trial in Europe and Australasia. Am J Transplant 2006;6:2912-2921.

58. Kappos L, Antel J, Comi G, et al. Oral fingolimod (FTY720) for relapsing multiple sclerosis. N Engl J Med 2006;355:1124-1140.

59. Hofmann M, Brinkmann V, Zerwes HG. FTY720 preferentially depletes naive $\mathrm{T}$ cells from peripheral and lymphoid organs. Int Immunopharmacol 2006;6:1902-1910.

60. Kimura A, Ohmori T, Ohkawa R, et al. Essential roles of sphingosine 1-phosphate/S1P1 receptor axis in the migration of neural stem cells toward a site of spinal cord injury. Stem Cells 2007; 25:115-124.

61. Pavlou AK, Belsey MJ. The therapeutic antibodies market to 2008. Eur J Pharm Biopharm 2005;59:389-396.

62. Presta LG. Engineering of therapeutic antibodies to minimize immunogenicity and optimize function. Adv Drug Deliv Rev 2006;58:640-656.

63. Hohlfeld R, Wekerle H. Drug Insight: using monoclonal antibodies to treat multiple sclerosis. Nat Clin Pract Neurol 2005; $1: 34-44$

64. Coles AJ, Cox A, Le Page E, et al. The window of therapeutic opportunity in multiple sclerosis: evidence from monoclonal antibody therapy. J Neurol 2006;253:98-108.

65. Moreau T, Thorpe J, Miller D, et al. Preliminary evidence from magnetic resonance imaging for reduction in disease activity after lymphocyte depletion in multiple sclerosis. Lancet 1994;344: 298-301.

66. Coles AJ, Wing MG, Molyneux P, et al. Monoclonal antibody treatment exposes three mechanisms underlying the clinical course of multiple sclerosis. Ann Neurol 1999;46:296-304.

67. Waldmann T, Tagaya Y, Bamford R. Interleukin-2, interleukin15, and their receptors. Int Rev Immunol 1998;16:205-226.

68. Waldmann TA. The IL-2/IL-15 receptor systems: targets for immunotherapy. J Clin Immunol 2002;22:51-56.

69. Goebel J, Stevens E, Forrest K, Roszman TL. Daclizumab (Zenapax) inhibits early interleukin-2 receptor signal transduction events. Transpl Immunol 2000;8:153-159.

70. Tkaczuk J, Milford E, Yu C, et al. Intracellular signaling consequences of anti-IL-2Ralpha blockade by daclizumab. Transplant Proc 2001;33:212-213.

71. Queen C, Schneider WP, Selick HE, et al. A humanized antibody that binds to the interleukin 2 receptor. Proc Natl Acad Sci U S A 1989;86:10029-10033.

72. Waldmann TA, O'Shea J. The use of antibodies against the IL-2 receptor in transplantation. Curr Opin Immunol 1998;10:507-512.

73. Nussenblatt RB, Fortin E, Schiffman R, et al. Treatment of noninfectious intermediate and posterior uveitis with the humanized anti-Tac mAb: a phase I/II clinical trial. Proc Natl Acad Sci U S A 1999;96:7462-7466.

74. Nussenblatt RB, Thompson DJ, Li Z, et al. Humanized antiinterleukin-2 (IL-2) receptor alpha therapy: long-term results in uveitis patients and preliminary safety and activity data for establishing parameters for subcutaneous administration. J Autoimmun 2003;21:283-293. 
75. Bielekova B, Richert N, Howard T, et al. Humanized anti-CD25 (daclizumab) inhibits disease activity in multiple sclerosis patients failing to respond to interferon \{beta\}. Proc Natl Acad Sci U S A 2004;101:8705-8708.

76. Rose JW, Watt HE, White AT, Carlson NG. Treatment of multiple sclerosis with an anti-interleukin-2 receptor monoclonal antibody. Ann Neurol 2004;56:864-867.

77. Bielekova B, Catalfamo M, Reichert-Scrivner S, et al. Regulatory CD56 bright natural killer cells mediate immunomodulatory effects of IL-2R $\{$ alpha $\}$-targeted therapy (daclizumab) in multiple sclerosis. PNAS 2006;103:5941-5946.

78. Rice GP, Hartung HP, Calabresi PA. Anti-alpha4 integrin therapy for multiple sclerosis: mechanisms and rationale. Neurology 2005;64:1336-1342.

79. Tubridy N, Behan PO, Capildeo R, et al. The effect of anti-alpha4 integrin antibody on brain lesion activity in MS. The UK Antegren Study Group. Neurology 1999;53:466-472.

80. Miller DH, Khan OA, Sheremata WA, et al. A controlled trial of natalizumab for relapsing multiple sclerosis. N Engl J Med 2003; 348:15-23.

81. O'Connor PW, Goodman A, Willmer-Hulme AJ, et al. Randomized multicenter trial of natalizumab in acute MS relapses: clinical and MRI effects. Neurology 2004;62:2038-2043.

82. Polman $\mathrm{CH}$, O'Connor PW, Havrdova E, et al. A randomized, placebo-controlled trial of natalizumab for relapsing multiple sclerosis. N Engl J Med 2006;354:899-910.

83. Rudick RA, Stuart WH, Calabresi PA, et al. Natalizumab plus interferon beta-1a for relapsing multiple sclerosis. N Engl J Med 2006;354:911-923.

84. Jacobs LD, Cookfair DL, Rudick RA, et al. Intramuscular interferon beta-1a for disease progression in multiple sclerosis. Ann Neurol 1996;39:285-294.

85. Yousry TA, Major EO, Ryschkewitsch C, et al. Evaluation of patients treated with natalizumab for progressive multifocal leukoencephalopathy. N Engl J Med 2006;354:924-933.

86. Niino M, Bodner C, Simard ML, et al. Natalizumab effects on immune cell responses in multiple sclerosis. Ann Neurol 2006; 59:748-754

87. Stuve $\mathrm{O}$, Marra $\mathrm{CM}$, Jerome KR, et al. Immune surveillance in multiple sclerosis patients treated with natalizumab. Ann Neurol 2006;59:743-747.

88. Cross AH, Stark JL, Lauber J, Ramsbottom MJ, Lyons JA. Rituximab reduces $B$ cells and $T$ cells in cerebrospinal fluid of multiple sclerosis patients. J Neuroimmunol 2006;180:63-70.

89. Stuve O, Cepok S, Elias B, et al. Clinical stabilization and effective B-lymphocyte depletion in the cerebrospinal fluid and peripheral blood of a patient with fulminant relapsing-remitting multiple sclerosis. Arch Neurol 2005;62:1620-1623.

90. Soon D, Altmann DR, Fernando KT, et al. A study of subtle blood brain barrier disruption in a placebo-controlled trial of natalizumab in relapsing remitting multiple sclerosis. J Neurol 2007; 254:306-314.

91. Stuve O, Marra CM, Bar-Or A, et al. Altered CD4+/CD8+ $\mathrm{T}$-cell ratios in cerebrospinal fluid of natalizumab-treated patients with multiple sclerosis. Arch Neurol 2006;63:1383-1387.

92. Rastetter W, Molina A, White CA. Rituximab: expanding role in therapy for lymphomas and autoimmune diseases. Annu Rev Med 2004;55:477-503.

93. Tedder TF, Engel P. CD20: a regulator of cell-cycle progression of B lymphocytes. Immunol Today 1994;15:450-454.
94. McLaughlin P, Grillo-Lopez AJ, Link BK, et al. Rituximab chimeric anti-CD20 monoclonal antibody therapy for relapsed indolent lymphoma: half of patients respond to a four-dose treatment program. J Clin Oncol 1998;16:2825-2833.

95. Taylor RP, Lindorfer MA. Drug insight: the mechanism of action of rituximab in autoimmune disease-the immune complex decoy hypothesis. Nat Clin Pract Rheumatol 2007;3:86-95.

96. Monson NL, Cravens PD, Frohman EM, Hawker K, Racke MK. Effect of rituximab on the peripheral blood and cerebrospinal fluid B cells in patients with primary progressive multiple sclerosis. Arch Neurol 2005;62:258-264.

97. Chang A, Tourtellotte WW, Rudick R, Trapp BD. Premyelinating oligodendrocytes in chronic lesions of multiple sclerosis. N Engl J Med 2002;346:165-173.

98. Lucchinetti C, Bruck W, Parisi J, Scheithauer B, Rodriguez M, Lassmann H. Heterogeneity of multiple sclerosis lesions: implications for the pathogenesis of demyelination. Ann Neurol 2000; 47:707-717.

99. Bjartmar C, Wujek JR, Trapp BD. Axonal loss in the pathology of MS: consequences for understanding the progressive phase of the disease. J Neurol Sci 2003;206:165-171.

100. Trebst C, Stangel M. Promotion of remyelination by immunoglobulins: implications for the treatment of multiple sclerosis. Curr Pharm Des 2006;12:241-249.

101. Rodriguez M, Lennon VA. Immunoglobulins promote remyelination in the central nervous system. Ann Neurol 1990;27:12-17.

102. Stangel M, Boegner F, Klatt CH, Hofmeister C, Seyfert S. Placebo controlled pilot trial to study the remyelinating potential of intravenous immunoglobulins in multiple sclerosis. J Neurol Neurosurg Psychiatry 2000;68:89-92.

103. Noseworthy JH, O'Brien PC, Weinshenker BG, et al. IV immunoglobulin does not reverse established weakness in MS. Neurology 2000;55:1135-1143.

104. Noseworthy JH, O'Brien PC, Petterson TM, et al. A randomized trial of intravenous immunoglobulin in inflammatory demyelinating optic neuritis. Neurology 2001;56:1514-1522.

105. Hommes OR, Sorensen PS, Fazekas F, et al. Intravenous immunoglobulin in secondary progressive multiple sclerosis: randomised placebo-controlled trial. Lancet 2004;364:1149-1156.

106. Fazekas F, Sorensen PS, Filippi M, et al. MRI results from the European Study on Intravenous Immunoglobulin in Secondary Progressive Multiple Sclerosis (ESIMS). Mult Scler 2005;11: 433-440.

107. Warrington AE, Asakura K, Bieber AJ, et al. Human monoclonal antibodies reactive to oligodendrocytes promote remyelination in a model of multiple sclerosis. Proc Natl Acad Sci U S A 2000; 97:6820-6825.

108. Warrington AE, Bieber AJ, Ciric B, et al. Immunoglobulin-mediated CNS repair. J Allergy Clin Immunol 2001;108:S121-125.

109. Pirko I, Ciric B, Gamez J, et al. A human antibody that promotes remyelination enters the CNS and decreases lesion load as detected by $\mathrm{T} 2$-weighted spinal cord MRI in a virus-induced murine model of MS. Faseb J 2004;18:1577-1579.

110. Warrington AE, Bieber AJ, Ciric B, Pease LR, Van Keulen V, Rodriguez M. A recombinant human IgM promotes myelin repair after a single, very low dose. J Neurosci Res 2007;85:967-976.

111. Ciric B, Howe CL, Paz Soldan M, et al. Human monoclonal IgM antibody promotes CNS myelin repair independent of FC function. Brain Pathol 2003;13:608-616. 